\title{
Towards Understanding the Different Influences of Grain Boundaries on Ion Transport in Sulfide and Oxide Solid Electrolytes
}

James Dawson, Pieremanuele Canepa, Matthew Clarke, Theodosios Famprikis, Dibyajyoti Ghosh, Saiful Islam

Submitted date: 02/05/2019 - Posted date: 03/05/2019

Licence: CC BY-NC-ND 4.0

Citation information: Dawson, James; Canepa, Pieremanuele; Clarke, Matthew; Famprikis, Theodosios; Ghosh, Dibyajyoti; Islam, Saiful (2019): Towards Understanding the Different Influences of Grain Boundaries on Ion Transport in Sulfide and Oxide Solid Electrolytes. ChemRxiv. Preprint.

Solid electrolytes provide a route to the development of all-solid-state batteries that can potentially surpass the safety and performance of conventional liquid electrolyte-based devices. Sulfide solid electrolytes have received particular attention as a result of their high ionic conductivities. One of the main reasons for such high ionic conductivity is the apparently reduced grain boundary resistance of sulfide solid electrolytes compared to their oxide counterparts, but this is not fully established. Using two model electrolyte systems, Na3PS4 and Na3PO4, we apply a novel microscale simulation approach to analyze ionic transport in polycrystalline materials with various grain volumes. For $\mathrm{Na3PO} 4$, high grain boundary resistance is found, with the $\mathrm{Na}$-ion conductivity decreasing with decreasing grain volume. For Na3PS4, the overall influence of grain boundaries is significantly reduced compared to the oxide. Detailed analysis reveals a minimal change in the local structures and $\mathrm{Na}$-ion conduction mechanism between bulk and polycrystalline Na3PS4, whereas the change is far more substantial for $\mathrm{Na3PO}$, with evidence of over-coordination of $\mathrm{Na}$ ions at the grain boundaries. Our microscale approach helps to explain the fundamentally different influences of grain boundaries on ion transport in phosphate and thiophosphate solid electrolytes.

File list (2)

poly ACS.pdf (1.30 MiB)

view on ChemRxiv - download file

poly-SI.pdf $(820.52 \mathrm{KiB})$

view on ChemRxiv - download file 


\title{
Towards Understanding the Different Influences of Grain Boundaries on Ion Transport in Sulfide and Oxide Solid Electrolytes
}

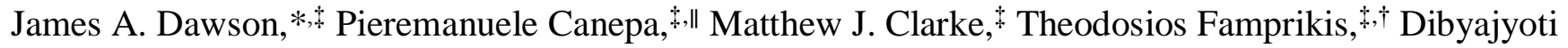 \\ Ghosh ${ }^{\ddagger}$ and M. Saiful Islam*, \\ \#Department of Chemistry, University of Bath, Bath, BA2 7AY, UK \\ †Laboratoire de Réactivité et de Chimie des Solides (UMR CNRS 7314), Université de Picardie Jules Verne, 33 rue \\ Saint Leu, 80039 Amiens Cedex, France
}

Supporting Information Placeholder

\begin{abstract}
Solid electrolytes provide a route to the development of all-solid-state batteries that can potentially surpass the safety and performance of conventional liquid electrolyte-based devices. Sulfide solid electrolytes have received particular attention as a result of their high ionic conductivities. One of the main reasons for such high ionic conductivity is the apparently reduced grain boundary resistance of sulfide solid electrolytes compared to their oxide counterparts, but this is not fully established. Using two model electrolyte systems, $\mathrm{Na}_{3} \mathrm{PS}_{4}$ and $\mathrm{Na}_{3} \mathrm{PO}_{4}$, we apply a novel microscale simulation approach to analyze ionic transport in polycrystalline materials with various grain volumes. For $\mathrm{Na}_{3} \mathrm{PO}_{4}$, high grain boundary resistance is found, with the Na-ion conductivity decreasing with decreasing grain volume. For $\mathrm{Na}_{3} \mathrm{PS}_{4}$, the overall influence of grain boundaries is significantly reduced compared to the oxide. Detailed analysis reveals a minimal change in the local structures and Na-ion conduction mechanism between bulk and polycrystalline $\mathrm{Na}_{3} \mathrm{PS}_{4}$, whereas the change is far more substantial for $\mathrm{Na}_{3} \mathrm{PO}_{4}$, with evidence of over-coordination of $\mathrm{Na}$ ions at the grain boundaries. Our microscale approach helps to explain the fundamentally different influences of grain boundaries on ion transport in phosphate and thiophosphate solid electrolytes.
\end{abstract}

KEYWORDS: Solid electrolytes, grain boundaries, ion transport, solid-state batteries, interfacial resistance

Research into solid electrolytes for high-performance all-solid-state batteries has seen a dramatic rise in recent years. ${ }^{1-9}$ By replacing the flammable liquid electrolytes currently employed in commercial Li- and Na-ion batteries with solid electrolytes, the safety of the devices can be significantly enhanced, ${ }^{10}$ as well as providing an avenue to potentially improve their energy and power densities. A multitude of structural classes, including garnet, NASICON, LISICON, thioLISICON and perovskite structures, have been considered as solid electrolyte materials. ${ }^{6,11-17}$ Amongst these families of materials, $\mathrm{Li}$ - and $\mathrm{Na}$ - ion conducting thiophosphates, including $\mathrm{Li}_{10} \mathrm{MP}_{2} \mathrm{~S}_{12}(\mathrm{M}$ $=\mathrm{Ge}, \mathrm{Si}$ or $\mathrm{Sn}), \mathrm{Li}_{3} \mathrm{PS}_{4}, \mathrm{Na}_{3} \mathrm{PS}_{4}$ and $\mathrm{Na}_{11} \mathrm{Sn}_{2} \mathrm{PS}_{12}, 6,18-24$ have received significant interest due to their intrinsic soft mechanical nature and fast-ion conduction.3,25

In oxide-based solid electrolytes, grain boundaries (GBs) are generally considered to inhibit ion migration and therefore represent a substantial hurdle for fast-ion conduction. ${ }^{14,16}$ For sulfide-based solid electrolytes, the influence of GBs on the overall ion transport is not as clear, with conflicting reports of GBs that either hinder ionic conduction ${ }^{20,26,27}$ or have no significant effect on ionic conduction..$^{20,21,28,29}$ In any case, it is frequently observed that oxides show larger GB resistance than sulfides. ${ }^{30-32}$ GBs are also important microstructural features that are linked to dendrite formation and penetration, ${ }^{33-35}$ and defect segregation ${ }^{36}$ Furthermore, there is growing interest in glass-ceramic ion conductors, where the roles of nanocrystallite and GB effects are not clear. ${ }^{37,38}$ Although many reports discuss the influence of GB resistance on ionic conductivity, its origins and mechanisms are not entirely understood, particularly at the atomic scale.

$\mathrm{Na}_{3} \mathrm{PS}_{4}$ has recently experienced a resurgence in interest, ${ }^{21,39-47}$ primarily as a result of the work of Hayashi et al. ${ }^{26,48}$ who synthesized a stable glassceramic cubic phase at room temperature with an unprecedented $\mathrm{Na}$-ion conductivity of $2 \times 10^{-4} \mathrm{~S} \mathrm{~cm}^{-1}$. 
Krauskopf et al. ${ }^{21}$ report that the influence of GBs appears to be small in these mechanically soft materials. Small GB resistances have also been reported for other well-known sulfide solid electrolytes, such as the argyrodite $\mathrm{Li}_{6} \mathrm{PS}_{5} \mathrm{Br}^{49}$ and $\mathrm{Li}_{10} \mathrm{GeP}_{2} \mathrm{~S}_{12 .}{ }^{20,29,50}$ Conversely, earlier studies have speculated that the Na-ion conductivity of $\mathrm{Na}_{3} \mathrm{PS}_{4}$ is influenced by grain boundaries. ${ }^{26,27}$ Although $\mathrm{Na}_{3} \mathrm{PO}_{4}$ has been studied for over four decades as a solid electrolyte, ${ }^{51-53}$ its GB resistance has not been fully characterized.

In this study, we elucidate the role of GBs in the transport of ions in solid electrolytes by proposing a novel microscale strategy based on large-scale molecular dynamics (MD) simulations. We apply this method to analyze these two well-known polycrystalline model systems, $\mathrm{Na}_{3} \mathrm{PS}_{4}$ and $\mathrm{Na}_{3} \mathrm{PO}_{4}$, with various grain volumes, in order to elucidate the different contributions of GB resistance in sulfide and oxide solid electrolytes. Our findings show high GB resistance for $\mathrm{Na}_{3} \mathrm{PO}_{4}$, but for $\mathrm{Na}_{3} \mathrm{PS}_{4}$, the relationship between ion transport and grain volume is weaker. Structural and mechanistic results reveal pronounced differences between the local environments of the ions at the GBs of $\mathrm{Na}_{3} \mathrm{PO}_{4}$, while for $\mathrm{Na}_{3} \mathrm{PS}_{4}$, these differences are minimized. This novel microscale approach illustrates the fundamentally different influences of grain boundaries on ion transport at the atomic scale in sulfide and oxide solid electrolytes.

\section{RESULTS AND DISCUSSION}

Structures and Na-ion conductivity of bulk $\mathrm{Na}_{3} \mathrm{PS}_{4}$ and $\mathrm{Na}_{3} \mathrm{PO}_{4}$. Two crystal polymorphs are known for $\mathrm{Na}_{3} \mathrm{PS}_{4}$ : a tetragonal phase with space group $P \overline{4} 2_{1} c$ and lattice parameters of $a=6.952 \AA$ and $c=7.076 \AA, 54$ and a cubic phase with space group $I \overline{4} 3 \mathrm{~m}$ and a lattice parameter of $a=6.989 \AA \AA^{21}$ These polymorphs are very similar, with minor differences in the orientation of the $\mathrm{PS}_{4}$ tetrahedra and the corresponding positions of the Na ions. Furthermore, they also exhibit similar $\mathrm{Na}$-ion conductivities, ${ }^{21,39}$ although earlier studies have reported higher conductivities for the cubic phase. ${ }^{26,27}$ Similarly, a tetragonal phase with space group $P \overline{4} 2_{1} c$ and lattice parameters of $a=10.811 \AA$ and $c=6.818 \AA, 55$ and $a$ cubic phase with space group $F m \overline{3} m$ and a lattice parameter of $a=7.544 \AA 55$ also exist for $\mathrm{Na}_{3} \mathrm{PO}_{4}$. The tetragonal-cubic transition for $\mathrm{Na}_{3} \mathrm{PO}_{4}$ results in a sudden increase in Na-ion conductivity. 55

In this work, we focus on the cubic polymorphs as the crystallographic similarities between cubic $\mathrm{Na}_{3} \mathrm{PS}_{4}$ and $\mathrm{Na}_{3} \mathrm{PO}_{4}$ allow us to examine key GB effects. The calculated lattice parameters for cubic
$\mathrm{Na}_{3} \mathrm{PS}_{4}$ and $\mathrm{Na}_{3} \mathrm{PO}_{4}$ are 6.992 and $7.524 \AA$, respectively, in excellent agreement with experimental data. ${ }^{20,55}$ The agreement between the experimental and calculated bond distances is also excellent, as shown in the supporting information.

Figure 1 shows the Arrhenius plots for the calculated Na-ion conductivity for bulk $\mathrm{Na}_{3} \mathrm{PS}_{4}$ and $\mathrm{Na}_{3} \mathrm{PO}_{4}$. Mean squared displacement (MSD) plots for Na-ion diffusion in bulk $\mathrm{Na}_{3} \mathrm{PS}_{4}$ and $\mathrm{Na}_{3} \mathrm{PO}_{4}$ are given in Figure $\mathrm{S}$. We find that the Na-ion conductivity is higher in the sulfide than the oxide, with calculated bulk conductivities of $3.42 \times 10^{-4}$ and $9.18 \times 10^{-5} \mathrm{~S} \mathrm{~cm}^{-1}$ for $\mathrm{Na}_{3} \mathrm{PS}_{4}$ and $\mathrm{Na}_{3} \mathrm{PO}_{4}$, respectively, at $400 \mathrm{~K}$.

Our conductivity measurements are in good agreement with the impedance measurements of Krauskopf et al. ${ }^{21}$ for tetragonal $\mathrm{Na}_{3} \mathrm{PS}_{4}$ obtained from a high-temperature solid-state synthetic route $\left(\sim 8 \times 10^{-}\right.$ $5 \mathrm{~S} \mathrm{~cm}^{-1}$ at $333 \mathrm{~K}$ ) and Yu et al. ${ }^{27}$ for cubic and tetragonal $\mathrm{Na}_{3} \mathrm{PS}_{4}\left(\sim 1 \times 10^{-4}\right.$ and $\sim 1 \times 10^{-5} \mathrm{~S} \mathrm{~cm}^{-1}$ at $300 \mathrm{~K}$, respectively). The calculated activation energy of 0.27 $\mathrm{eV}$ for $\mathrm{Na}_{3} \mathrm{PS}_{4}$ agrees well with the value of $0.28 \mathrm{eV}$ derived from impedance measurements. ${ }^{26}$

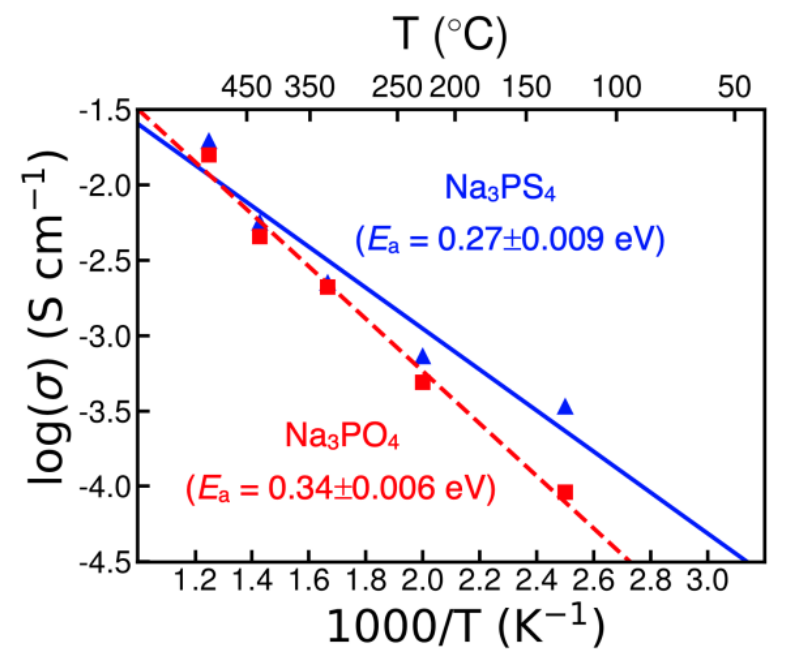

Figure 1. Na-ion conductivities $(\sigma)$ and activation energies $\left(E_{\mathrm{a}}\right)$ for bulk $\mathrm{Na}_{3} \mathrm{PS}_{4}$ and $\mathrm{Na}_{3} \mathrm{PO}_{4}$.

A conductivity of $2.1 \times 10^{-3} \mathrm{~S} \mathrm{~cm}^{-1}$ was found for $\mathrm{Na}_{3} \mathrm{PO}_{4}$ at $600 \mathrm{~K}$. This is in agreement with the value of $\sim 1 \times 10^{-3} \mathrm{~S} \mathrm{~cm}^{-1}$ obtained from impedance values at the same temperature. ${ }^{52,56}$ Our calculated activation energy of $0.34 \mathrm{eV}$ is slightly lower than the experimental value of $0.42 \mathrm{eV} .^{52,56}$

Na-ion conductivity of polycrystalline $\mathrm{Na}_{3} \mathrm{PS}_{4}$ and $\mathrm{Na}_{3} \mathrm{PO}_{4}$. To assess the impact of GBs on the Naion conductivity of the model $\mathrm{Na}_{3} \mathrm{PS}_{4}$ and $\mathrm{Na}_{3} \mathrm{PO}_{4}$ systems, we investigated polycrystalline systems with different grain volumes. The grain volumes are calculated by simply dividing the total volume of the polycrystal by the number of grains. Figures 2(a) and (b) shows the Arrhenius plots for the calculated Na- 
ion conductivity for bulk and polycrystalline $\mathrm{Na}_{3} \mathrm{PS}_{4}$ and $\mathrm{Na}_{3} \mathrm{PO}_{4}$, respectively. Example MSD plots for $\mathrm{Na}-$ ion diffusion in polycrystalline $\mathrm{Na}_{3} \mathrm{PS}_{4}$ and $\mathrm{Na}_{3} \mathrm{PO}_{4}$ are given in Figure S2.

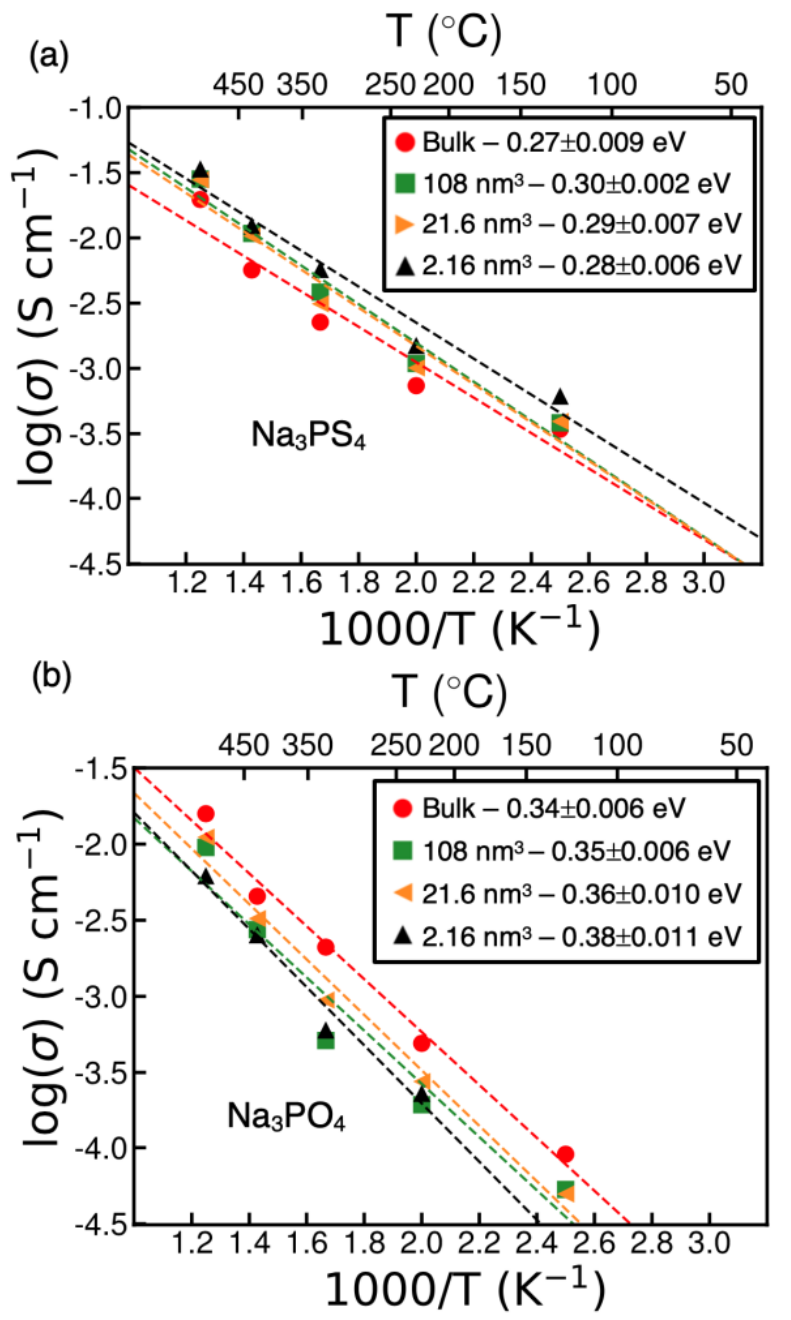

Figure 2. Na-ion conductivities $(\sigma)$ and activation energies $\left(E_{a}\right)$ for bulk and polycrystalline (for three different grain volumes of 108, 21.6 and $2.16 \mathrm{~nm}^{3}$ ) (a) $\mathrm{Na}_{3} \mathrm{PS}_{4}$ and (b) $\mathrm{Na}_{3} \mathrm{PO}_{4}$. Conductivity data for all five grain volumes is given in Figure $\mathrm{S}_{3}$.

The Arrhenius plots for $\mathrm{Na}_{3} \mathrm{PS}_{4}$ in Figure 2(a) reveal two important findings. First, the conductivities for the polycrystalline systems are higher than for bulk $\mathrm{Na}_{3} \mathrm{PS}_{4}$. The highest conductivities are found for polycrystals with the smallest grain volume of 2.16 $\mathrm{nm}^{3}$, with values of $6.15 \times 10^{-4}$ and $3.38 \times 10^{-2} \mathrm{~S} \mathrm{~cm}^{-1}$ at 400 and $800 \mathrm{~K}$, respectively, compared to the bulk conductivities of $3.42 \times 10^{-4}$ and $1.97 \times 10^{-2} \mathrm{~S} \mathrm{~cm}^{-1}$ at 400 and $800 \mathrm{~K}$, respectively. Furthermore, when the conductivities of the polycrystals of $\mathrm{Na}_{3} \mathrm{PS}_{4}$ are extrapolated to room temperature, they are very similar to the bulk conductivity. These results suggest that GB resistance in $\mathrm{Na}_{3} \mathrm{PS}_{4}$ is indeed weak, as proposed in recent impedance experiments of this mechanically soft material. ${ }^{21}$
Second, the calculated activation energies are all similar for the polycrystals of $\mathrm{Na}_{3} \mathrm{PS}_{4}(0.28-0.30 \mathrm{eV})$ compared to the bulk value of $0.27 \mathrm{eV}$, which suggests that the overall influence of GBs on Na-ion transport in this material is minimal.

In contrast, Figure 2 (b) shows a reduction in conductivity and a small increase in activation energy for all the $\mathrm{Na}_{3} \mathrm{PO}_{4}$ polycrystalline systems compared to the bulk. The lowest conductivities are obtained for the systems with the smallest grain volume, reaching $2.24 \times 10^{-5}$ and $6.20 \times 10^{-3} \mathrm{~S} \mathrm{~cm}^{-1}$ at 400 and $800 \mathrm{~K}$, respectively. These values are significantly lower than the bulk conductivities of $9.19 \times 10^{-5}$ and $1.58 \times 10^{-2} \mathrm{~S} \mathrm{~cm}^{-}$ ${ }^{1}$ at 400 and $800 \mathrm{~K}$, respectively. Furthermore, there is a relationship between the activation energy and the grain volume, with a rising trend in activation energy from bulk $\mathrm{Na}_{3} \mathrm{PO}_{4}$ to the $\mathrm{Na}_{3} \mathrm{PO}_{4}$ polycrystal with the smallest grain volume of $2.16 \mathrm{~nm}^{3}$.

We have previously demonstrated the important role of the GB resistance in the fast-ion conductor, $\mathrm{Li}_{3} \mathrm{OCl}$, which allowed us to provide accurate estimates of ionic conductivities and activation barriers in agreement with experimental data. ${ }^{16}$ The results from Figure 2(b) provide evidence of GB resistance in $\mathrm{Na}_{3} \mathrm{PO}_{4}$. Although we are not aware of any experimental characterization of GB resistance specifically in $\mathrm{Na}_{3} \mathrm{PO}_{4}$, significant GB resistance for the majority of oxide-based $\mathrm{Li}$ - and $\mathrm{Na}$-ion fast conductors is well documented. ${ }^{5,16,30,57-59}$

Figure 3 shows the activation energies for bulk and polycrystalline $\mathrm{Na}_{3} \mathrm{PS}_{4}$ and $\mathrm{Na}_{3} \mathrm{PO}_{4}$ as a function of grain volume. The activation energies decrease for $\mathrm{Na}_{3} \mathrm{PO}_{4}$, but increase for $\mathrm{Na}_{3} \mathrm{PS}_{4}$, as the grain volume becomes larger. These findings highlight the opposing influences of GBs on Na-ion transport in sulfide and oxide solid electrolytes.

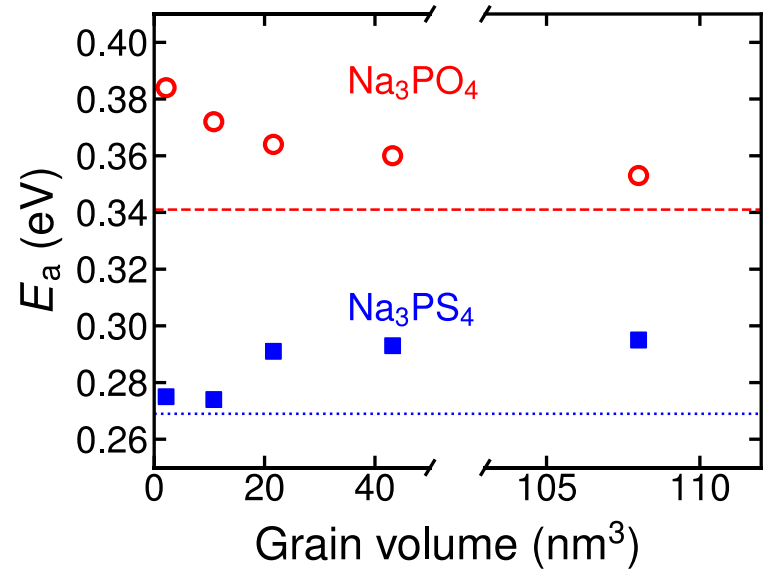

Figure 3. Activation energies $\left(E_{\mathrm{a}}\right)$ for bulk (dashed lines) and polycrystalline $\mathrm{Na}_{3} \mathrm{PS}_{4}$ (squares) and $\mathrm{Na}_{3} \mathrm{PO}_{4}$ (circles) as a function of grain volume. 
In order to confirm the trends between conductivity, activation energy and grain volume discussed above, we also carried out a number of test simulations with $125 \times 125 \times 125 \AA^{3}$ cells containing 80000-1200oo ions, thereby increasing the grain volumes by almost an order of magnitude. Arrhenius plots for the conductivities obtained from these calculations with grain volumes of 976.56, 195.31 and $19.53 \mathrm{~nm}^{3}$ (equivalent to 2,10 and 100 grains, respectively) at 400, 600 and $800 \mathrm{~K}$ are given in Figure S4. From these results, it is clear that the same trends are observed as in Figures 2 and 3, namely, decreasing conductivity and increasing activation energy with decreasing grain volume for the oxide and increasing conductivity with decreasing grain volume for the sulfide.

In summary, our results show two distinct and opposing behaviors for the effect of GBs on Na-ion conduction in two model sulfide and oxide solid electrolytes.

Local structural insights into GB effects. The analysis of ion transport presented here shows the distinctly different influences of GBs on ion conduction in $\mathrm{Na}_{3} \mathrm{PS}_{4}$ and $\mathrm{Na}_{3} \mathrm{PO}_{4}$; however, the underlying reasons for these differences are not fully understood. To probe the local structural factors, we analyze the radial distribution functions (RDFs) for $\mathrm{Na}-\mathrm{Na}, \mathrm{Na}-\mathrm{P}$ and $\mathrm{Na}-\mathrm{S} / \mathrm{O}$ in the bulk materials and the polycrystals with the largest $\left(108 \mathrm{~nm}^{3}\right)$ and smallest $\left(2.16 \mathrm{~nm}^{3}\right)$ grain volumes. The RDFs for both $\mathrm{Na}_{3} \mathrm{PS}_{4}$ and $\mathrm{Na}_{3} \mathrm{PO}_{4}$ at $400 \mathrm{~K}$ are displayed in Figure 4.

First considering $\mathrm{Na}_{3} \mathrm{PS}_{4}$, the bulk and polycrystal systems show a sharp primary peak at $\sim 3.3 \AA$ in their $\mathrm{Na}-\mathrm{Na}$ RDFs. For the polycrystals, these peaks are higher, marginally broadened and their distance reduced by $\sim 0.1 \AA$, compared to the bulk. These features suggest that the GBs in $\mathrm{Na}_{3} \mathrm{PS}_{4}$ allow the $\mathrm{Na}$ ions to be closer to each other. It is noteworthy that the Na-Na RDFs for the $\mathrm{Na}_{3} \mathrm{PS}_{4}$ polycrystals with the largest and smallest grain volumes are almost identical, suggesting that the difference between the conductivities of these polycrystals is not a primary result of the $\mathrm{Na}$ distributions. This is in agreement with the ab initio MD results of de Klerk and Wagemaker. ${ }^{39}$ The Na-P RDFs for the bulk and polycrystals of $\mathrm{Na}_{3} \mathrm{PS}_{4}$ show comparable behavior. The Na-S RDFs for $\mathrm{Na}_{3} \mathrm{PS}_{4}$ are almost identical for each system, with similar trends to those previously observed for RDFs of successful Na-ion hopping. ${ }^{39}$

Overall, the RDFs for bulk and polycrystalline $\mathrm{Na}_{3} \mathrm{PS}_{4}$ are strikingly congruent, which strongly suggests that there is no substantial change in the conduction mechanism as a result of the GBs. This is further corroborated by the fact that the RDFs of the polycrystals are almost indistinguishable. These results again advocate that it is the point defect concentrations and compositional changes between these sulfide structures that are responsible for the small changes in Na-ion transport characteristics and not the GBs themselves.
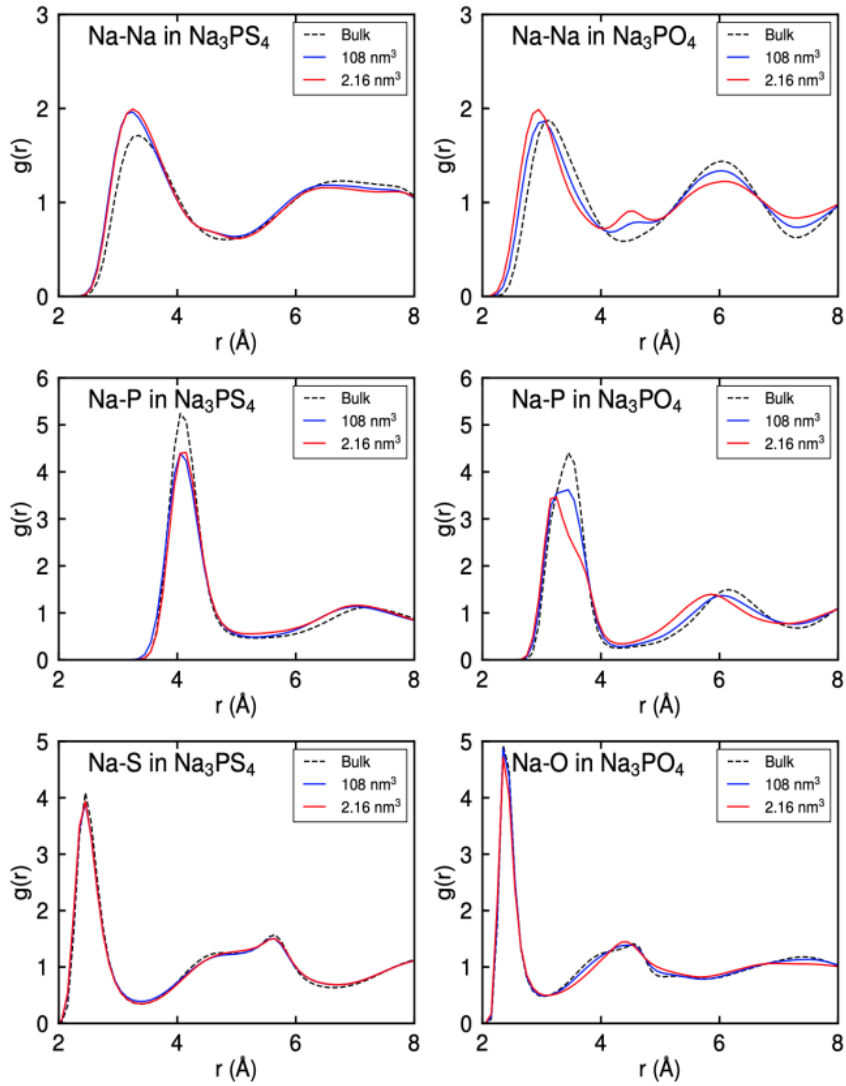

Figure 4. Na-Na, Na-P and Na-S/O RDFs for bulk and polycrystalline (grain volumes of 108 and 2.16 $\left.\mathrm{nm}^{3}\right) \mathrm{Na}_{3} \mathrm{PS}_{4}$ (left) and $\mathrm{Na}_{3} \mathrm{PO}_{4}$ (right) at $400 \mathrm{~K}$.

We now turn our attention to $\mathrm{Na}_{3} \mathrm{PO}_{4}$. The bulk RDFs are in excellent agreement with previous MD studies. ${ }^{53}$ In contrast to $\mathrm{Na}_{3} \mathrm{PS}_{4}$, the $\mathrm{Na}-\mathrm{Na} \mathrm{RDF}$ for bulk and polycrystalline $\mathrm{Na}_{3} \mathrm{PO}_{4}$ show very different behavior. The Na-Na distances of the primary peaks are $3.15 \AA$ for the bulk and 3.05 and $2.95 \AA$ for the polycrystals with grain volumes of 108 and $2.16 \mathrm{~nm}^{3}$, respectively. This decrease in Na-Na distance is met with a corresponding increase in peak height for the polycrystal with the smallest grain volume of 2.16 $\mathrm{nm}^{3}$. With decreasing grain volume, a new peak appears at $\sim 4.5 \AA$, in addition to reductions of the peaks at Na-Na distances greater than $5 \AA$.

For the Na-P RDFs in $\mathrm{Na}_{3} \mathrm{PO}_{4}$, the main peaks at $3.5 \AA$ undergo substantial changes when moving from the bulk system to the polycrystals. The peaks become smaller and increasingly asymmetrical, particularly 
for the polycrystal with the smallest grain volume of $2.16 \mathrm{~nm}^{3}$ where a second peak on the right shoulder of the first peak becomes visible. Similar peak deformation has been observed for Na-P RDFs in $\mathrm{Na}_{3} \mathrm{PS}_{4}$, where de Klerk and Wagemaker ${ }^{39}$ associated the formation of two peaks at $\sim 3-5 \AA$ with unsuccessful Na-ion migration, since it results in a contraction of the free volume around the $\mathrm{Na}$ ions. Given that such behavior is indicative of unsuccessful hops, these results help to explain the reduced Na-ion conductivity that we observed as a function of grain volume for $\mathrm{Na}_{3} \mathrm{PO}_{4}$.

As with the Na-S RDFs for $\mathrm{Na}_{3} \mathrm{PS}_{4}$, the Na-O RDFs for $\mathrm{Na}_{3} \mathrm{PO}_{4}$ are all similar. Our structural analysis shows that the distributions of $\mathrm{Na}-\mathrm{S}$ and $\mathrm{Na}-$ $\mathrm{O}$ distances are not crucial factors in determining the changes in conductivity when comparing bulk and polycrystalline systems.

Analysis of the integrated RDFs provides useful information on the local coordination of a species. The integration of the Na-Na, Na-P and Na-S/Na-O RDFs for bulk and polycrystalline $\mathrm{Na}_{3} \mathrm{PS}_{4}$ and $\mathrm{Na}_{3} \mathrm{PO}_{4}$ at $400 \mathrm{~K}$ are given in Figure 5 .
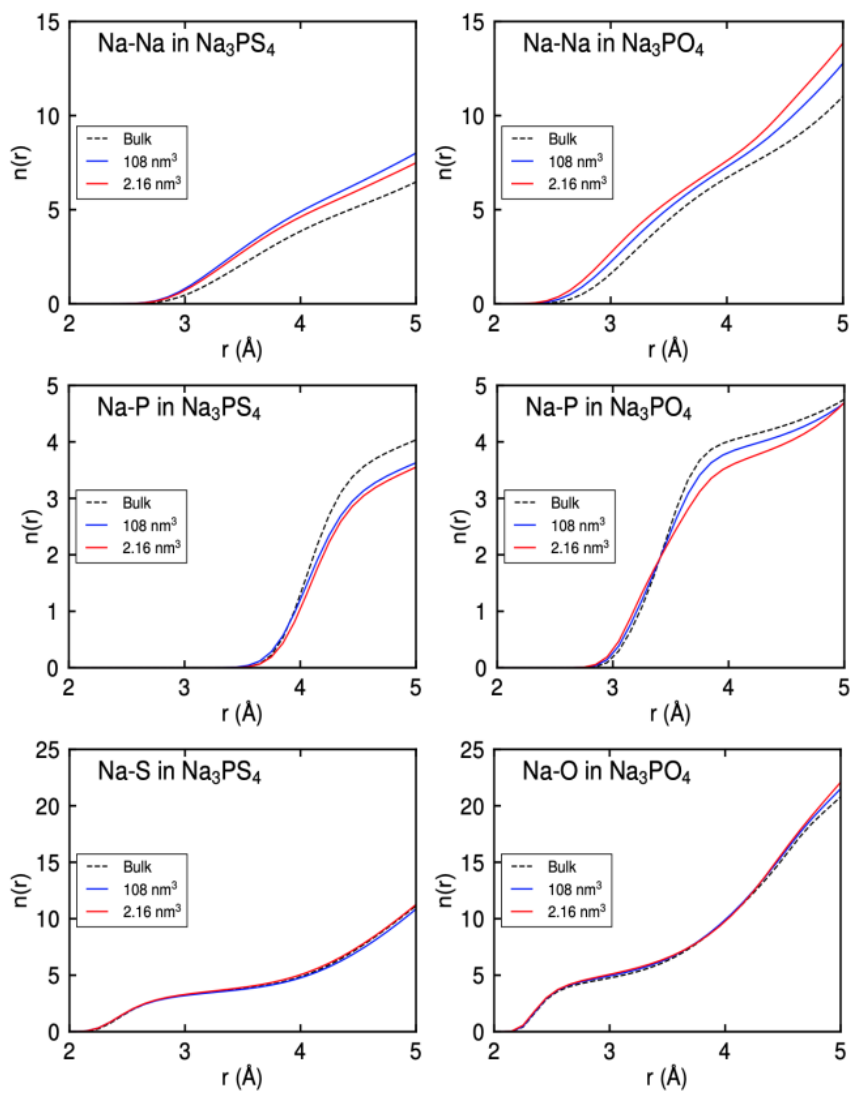

Figure 5. Integration of $\mathrm{Na}-\mathrm{Na}, \mathrm{Na}-\mathrm{P}$ and $\mathrm{Na}-\mathrm{S} / \mathrm{O}$ RDFs for bulk and polycrystalline (grain volumes of 108 and $2.16 \mathrm{~nm}^{3}$ ) $\mathrm{Na}_{3} \mathrm{PS}_{4}$ (left) and $\mathrm{Na}_{3} \mathrm{PO}_{4}$ (right) at $400 \mathrm{~K}$.
The main feature revealed from the data in Figure 5 is the difference in the coordination of $\mathrm{Na}$ ions to neighboring $\mathrm{Na}$ ions between the polycrystals of $\mathrm{Na}_{3} \mathrm{PS}_{4}$ and $\mathrm{Na}_{3} \mathrm{PO}_{4}$. For $\mathrm{Na}_{3} \mathrm{PS}_{4}$, the coordination number of $\mathrm{Na}$ ions to other $\mathrm{Na}$ ions is highest in the polycrystal with the largest grain volume of $108 \mathrm{~nm}^{3}$, whereas for $\mathrm{Na}_{3} \mathrm{PO}_{4}$, the polycrystal with the smallest grain volume of $2.16 \mathrm{~nm}^{3}$ has the highest coordination number. This fundamental difference indicates that $\mathrm{Na}$ ions effectively become under-coordinated with decreasing grain volume in $\mathrm{Na}_{3} \mathrm{PS}_{4}$, thereby providing potential for higher $\mathrm{Na}$-ion diffusion in these polycrystals.

In contrast, the opposite is true for $\mathrm{Na}_{3} \mathrm{PO}_{4}$, where the Na ions become over-coordinated with decreasing grain volume. These two opposing effects may help to explain the difference between the GB behavior of sulfide and oxide solid electrolytes. This under-/overcoordination effect is not seen for the $\mathrm{Na}-\mathrm{P}$ and $\mathrm{Na}-$ $\mathrm{S} / \mathrm{Na}-\mathrm{O}$ integrated RDFs, which suggests that it is the $\mathrm{Na}-\mathrm{Na}$ distributions at the GBs that play the major role in determining the $\mathrm{Na}$-ion conductivity in these systems.

In summary, this local structural analysis has clearly shown different behavior for the $\mathrm{Na}_{3} \mathrm{PS}_{4}$ and $\mathrm{Na}_{3} \mathrm{PO}_{4}$ electrolytes. For the sulfide, the differences between the RDFs of the bulk and polycrystalline systems are small, suggesting that the structural changes induced by the GBs do not have a dramatic effect on Na-ion transport. Conversely, for the oxide, the differences are much more pronounced. The GBs have a significant impact on the short- and long-range atomic distributions, suggesting a fundamental change in the Na-ion conduction mechanism of $\mathrm{Na}_{3} \mathrm{PO}_{4}$. These results help to explain the reasons why the impact of GBs on conductivity in sulfides is weaker than in oxides.

Na-ion conduction mechanisms. To clarify the underlying atomistic conduction mechanisms in these two materials and how the GBs affect these mechanisms, we produce density plots of the accumulated Na-ion trajectories over the simulated timescale, which are a powerful means of visualizing the migration pathways and all the positions in the lattice that are traversed.

Figure 6 shows the Na-ion diffusion density plots for selected regions of bulk $\mathrm{Na}_{3} \mathrm{PS}_{4}$ and $\mathrm{Na}_{3} \mathrm{PO}_{4}$ at 400 $\mathrm{K}$. As expected, significant long-range threedimensional $\mathrm{Na}$-ion diffusion is observed in both systems. A greater density of Na-ion diffusion pathways is observed for $\mathrm{Na}_{3} \mathrm{PS}_{4}$ compared to $\mathrm{Na}_{3} \mathrm{PO}_{4}$, in agreement with the faster $\mathrm{Na}$-ion diffusion of the sulfide system. The highest Na densities are observed 
at the crystallographic $\mathrm{Na}$ sites with significant oscillation. Both materials exhibit the same vacancy diffusion mechanism, where the $\mathrm{Na}$ ions vibrate around their own sites before migration to a nearby vacant site. Vacancy migration has been proposed previously for both $\mathrm{Na}_{3} \mathrm{PS}_{4}{ }^{39,44,60}$ and $\mathrm{Na}_{3} \mathrm{PO}_{4}{ }^{.51,53,55}$

(a)

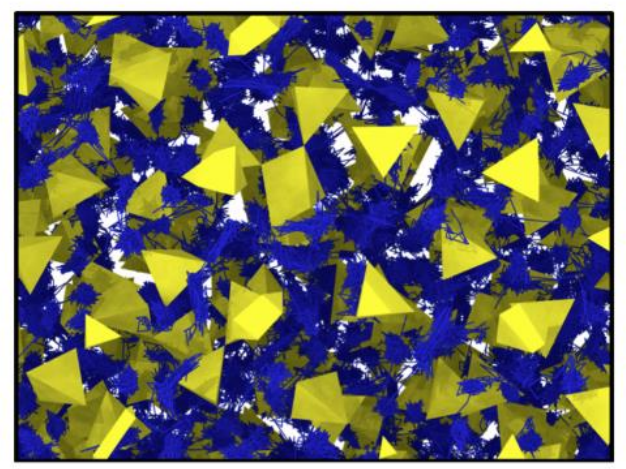

(b)

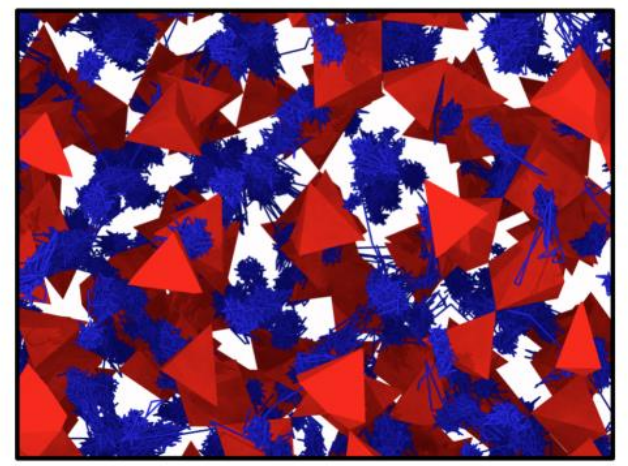

Figure 6. Diffusion density plots of Na ions (blue lines) overlaid on $\mathrm{PS}_{4}$ (yellow) and $\mathrm{PO}_{4}$ (red) tetrahedra in bulk (a) $\mathrm{Na}_{3} \mathrm{PS}_{4}$ and (b) $\mathrm{Na}_{3} \mathrm{PO}_{4}$, respectively, at $400 \mathrm{~K}$.

It has been proposed that $\mathrm{Na}$-ion diffusion in $\mathrm{Na}_{3} \mathrm{PO}_{4}$ can occur through the coupling of $\mathrm{Na}$ ions with the reorientation of their neighboring phosphate anions, i.e., the so-called "paddle-wheel" effect. ${ }^{61}$ In agreement with earlier MD studies, ${ }^{39,53,62}$ we find no strong evidence of this effect for either $\mathrm{Na}_{3} \mathrm{PO}_{4}$ or $\mathrm{Na}_{3} \mathrm{PS}_{4}$. As shown by the images in Figure $\mathrm{S}_{5}$, we do not observe any significant rotation of the $\mathrm{PS}_{4}$ and $\mathrm{PO}_{4}$ tetrahedra. Furthermore, correlated motions have been excluded for $\mathrm{Na}_{3} \mathrm{PO}_{4}$ on the basis of high-resolution neutron backscattering studies. ${ }^{63}$

We now turn our attention to Na-ion diffusion in the polycrystals. Figures 7 and 8 show the diffusion density plots of $\mathrm{Na}$ ions in $\mathrm{Na}_{3} \mathrm{PS}_{4}$ and $\mathrm{Na}_{3} \mathrm{PO}_{4}$ polycrystals with a grain volume of $108 \mathrm{~nm}^{3}$ (two grains), respectively, at $400 \mathrm{~K}$. Both grains (labelled 1 and 2) of the polycrystals are shown in separate images in order to better visualize $\mathrm{Na}$-ion diffusion at the GBs. Significant areas of intergranular diffusion (diffusion between different grains) are highlighted for $\mathrm{Na}_{3} \mathrm{PS}_{4}$. Figure 7 shows a higher level of $\mathrm{Na}$-ion diffusion at the GBs for $\mathrm{Na}_{3} \mathrm{PS}_{4}$ compared to $\mathrm{Na}_{3} \mathrm{PO}_{4}$ (Figure 8), as can be observed by the dense blue areas located at the edges of the grains of $\mathrm{Na}_{3} \mathrm{PS}_{4}$.

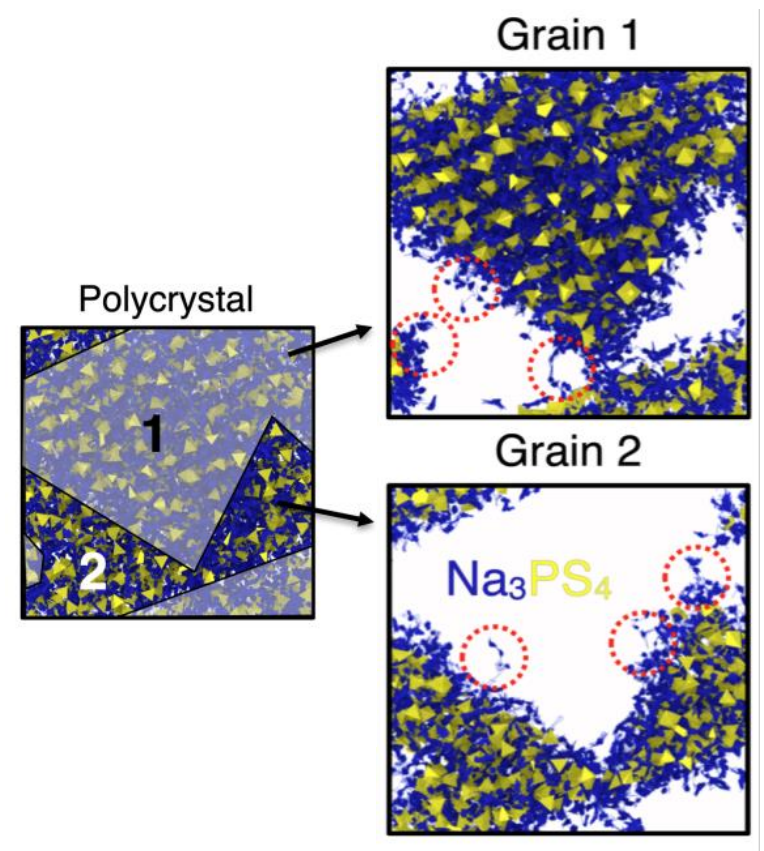

Figure 7. Diffusion density plots of Na ions overlaid on $\mathrm{PS}_{4}$ tetrahedra in $\mathrm{Na}_{3} \mathrm{PS}_{4}$ polycrystals with two grains at $400 \mathrm{~K}$. Red circles highlight areas of significant intergranular diffusion.

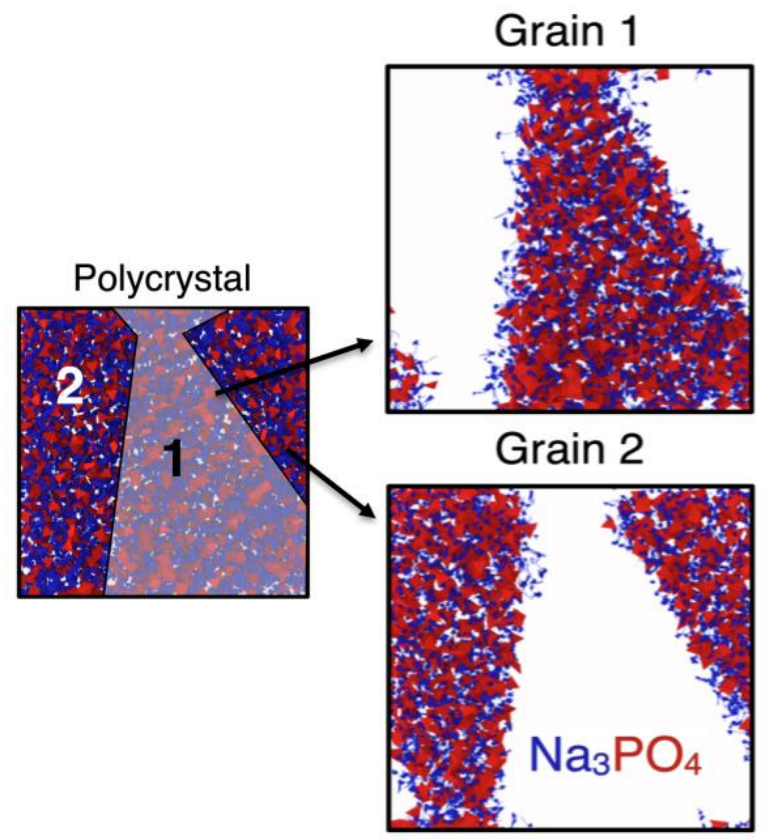

Figure 8. Diffusion density plots of $\mathrm{Na}$ ions overlaid on $\mathrm{PO}_{4}$ tetrahedra in $\mathrm{Na}_{3} \mathrm{PO}_{4}$ polycrystals with two grains at $400 \mathrm{~K}$.

In $\mathrm{Na}_{3} \mathrm{PO}_{4}$, the majority of Na-ion diffusion takes place within the grains, with very few $\mathrm{Na}$ ions hopping across the GBs from one grain to another. In contrast, intergranular diffusion is far more prevalent in $\mathrm{Na}_{3} \mathrm{PS}_{4}$, as highlighted by the red circles in Figure 7. 
These results strongly suggest that GBs in $\mathrm{Na}_{3} \mathrm{PS}_{4}$ do not restrict ion transport to the same extent as those of $\mathrm{Na}_{3} \mathrm{PO}_{4}$. Such findings are in complete agreement with our conductivity and structural analysis.

On this basis, it can be proposed that the undercoordination of conducting ions at the GBs of mechanically soft sulfides can be beneficial for conductivity, whereas for oxides, the overcoordination is detrimental for ion transport. These results help to explain the opposing effects of GBs in solid electrolytes reported in the literature. ${ }^{16,21,30,57}$

\section{CONCLUSIONS}

Grain boundary resistance is one of the key challenges that must be overcome for the successful utilization of all-solid-state batteries. It is generally accepted that grain boundary resistance is higher in oxides than sulfides; however, the underlying reasons for this are not fully understood. In this work, we have used a novel microscale simulation approach to identify and explain the fundamentally different influences of grain boundaries on ion transport in two model solid electrolytes, $\mathrm{Na}_{3} \mathrm{PS}_{4}$ and $\mathrm{Na}_{3} \mathrm{PO}_{4}$, with the following key results:

(a) High grain boundary resistance is found for $\mathrm{Na}_{3} \mathrm{PO}_{4}$, in which the Na-ion conductivity decreases with increasing grain volume.

(b) In contrast, the relationship between $\mathrm{Na}$-ion transport and grain volume is far weaker for $\mathrm{Na}_{3} \mathrm{PS}_{4}$. This suggests that for the sulfide it is the composition and point defect concentrations that are more important, in agreement with recent experimental findings.

(c) The local structures in bulk and polycrystalline $\mathrm{Na}_{3} \mathrm{PS}_{4}$ are very similar and help to explain the weak trend between its $\mathrm{Na}$-ion transport and grain volume. In contrast, the local structure of $\mathrm{Na}_{3} \mathrm{PO}_{4}$ exhibits distinct changes, including over-coordination around $\mathrm{Na}$ ions at the grain boundaries, indicative of a fundamental change in the ion conduction mechanism.

Our results help to clarify the opposing behavior of grain boundaries in phosphate-and thiophosphatebased solid electrolytes and their impact on ion conduction. Given the importance of interfaces in allsolid-state batteries, we propose that the microscale approach taken in this work can be widely applied to other solid electrolyte materials.

\section{METHODS}

The MD simulations are based on established techniques and have been widely used to determine the ion transport properties in a wide variety of $\mathrm{Li}$ and $\mathrm{Na}$-ion battery materials. ${ }^{16,62,64-68} \mathrm{~A}$ new potential model was developed for cubic $\mathrm{Na}_{3} \mathrm{PS}_{4}$ (Table $\mathrm{Si}$ ) using the empirical derivation procedure of the General Utility Lattice Program (GULP). ${ }^{69}$ For $\mathrm{Na}_{3} \mathrm{PO}_{4}$, we used the proven potential model of Tilocca et al. ${ }^{\circ 0}$ (Table S2) that was developed for MD calculations of phosphosilicate glasses, augmented here with a Na-Na interatomic potential from Harding. ${ }^{71}$ Formal valence charges for all ions and a potential cut-off of 12 Å were used. A full description of the potential models is available in the Supporting Information (Tables $\mathrm{S}_{1}-\mathrm{S}_{4}$ ).

The MD calculations were performed using LAMMPS. ${ }^{72}$ Long MD runs of 10 ns were completed using a time step of $1 \mathrm{fs}$ and supercells of 900o-13000 ions for both the bulk (single crystal) and polycrystal systems. Larger polycrystals of 8000o-1200oo ions were also tested in order to verify the trends determined for the smaller polycrystalline cells. Simulations were carried out for a temperature range of $400-800 \mathrm{~K}$ at intervals of $100 \mathrm{~K}$ using the NVT ensemble with a Nose-Hoover thermostat,73 with initial equilibration performed using the NPT ensemble for $\sim 2$ ns. We note that our calculations were carried out at elevated temperatures to improve computational efficiency.

Disorder was introduced to the bulk systems to promote long-range diffusion using $\mathrm{Na}$ vacancies (compensated by $\mathrm{S}$ or $\mathrm{O}$ vacancies) that were randomly distributed throughout the supercells at a concentration of $10 \%$. A lower $\mathrm{Na}$ vacancy concentration of $3 \%$ was also tested (see Figure S6), with only a minor reduction in Na-ion conductivity below $800 \mathrm{~K}$ and a minor increase in activation energy observed compared to the $10 \% \mathrm{Na}$ vacancy bulk systems. Such disorder was not introduced into the polycrystals as point defects were already present as a result of the GBs. The average stoichiometries of the polycrystals are given in Table $\mathrm{S}_{5}$. Self-diffusion data for $\mathrm{Na}$ were obtained from a mean squared displacement (MSD) analysis according to:

$$
\left\langle r_{i}^{2}(t)\right\rangle=6 D_{\mathrm{Na}} t
$$

where $\left\langle r_{i}^{2}(t)\right\rangle$ is the MSD, $D_{\mathrm{Na}}$ is the diffusion coefficient for $\mathrm{Na}$ and $t$ is time. The diffusion data were then converted to conductivities $(\sigma)$ using the Nernst-Einstein relationship:

$$
\overline{D_{\mathrm{Na}}}=H_{R} \frac{n q^{2}}{k T}
$$


where $n$ is the number of Na ions per unit volume, $q$ is the electron charge, $k$ is the Boltzmann constant, $T$ is the temperature and $H_{R}$ is the Haven ratio, which is set to 1 in our calculations.

The polycrystal models used in this study were constructed using Voronoi tessellations, as employed in the Atomsk program,74 in which nodes are introduced at given positions inside the simulation box that are then linked with their neighboring nodes. The normals to these links are then found and these define the contours of the randomly orientated grains, i.e., the GBs in this study. Unit cells are then placed at the nodes and are expanded in three dimensions. The final polycrystal is then obtained after the unit cells have been expanded and cut into the respective grains. The unit cell structures and example polycrystals for cubic $\mathrm{Na}_{3} \mathrm{PS}_{4}$ and $\mathrm{Na}_{3} \mathrm{PO}_{4}$ are given in Figure 9. Further details regarding the setup of the polycrystals for the MD simulations are given in the supporting information. (a)
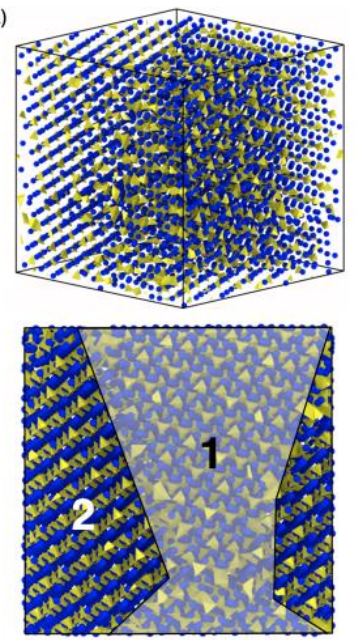

(b)

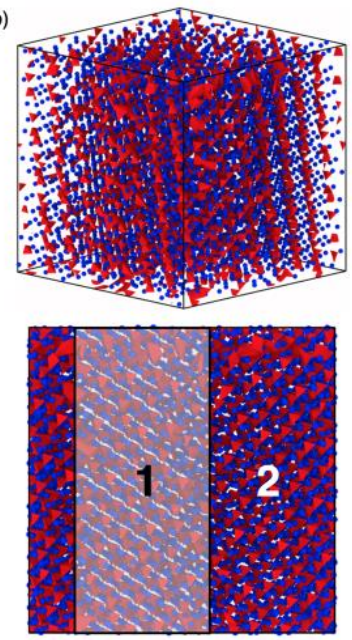

Figure 9. Example polycrystals containing two grains (grain volume of $108 \mathrm{~nm}^{3}$ ) for (a) $\mathrm{Na}_{3} \mathrm{PS}_{4}$ and (b) $\mathrm{Na}_{3} \mathrm{PO}_{4}$. The top images show the threedimensional polycrystals, while the bottom images indicate the approximate positions of the two grains. $\mathrm{Na}$ ions and $\mathrm{PS}_{4}$ and $\mathrm{PO}_{4}$ tetrahedra are given in blue, yellow and red, respectively.

Cubic polycrystals with dimensions of $60 \times 60 \times 60 \AA^{3}$ were used. Polycrystals with 2, 5, 10, 20 and 100 grains (equivalent to grain volumes of 108, 43.2, 21.6, 10.8 and $2.16 \mathrm{~nm}^{3}$, respectively) were used to investigate the effects of GBs on Na-ion transport in these systems. Example polycrystals with 2, 10 and 100 grains for $\mathrm{Na}_{3} \mathrm{PS}_{4}$ are illustrated in Figure 10. MD simulations were carried out on three different random polycrystals for each grain volume and the data were averaged. The variance in conductivity between the random three polycrystals for each grain volume was minimal, as detailed in Tables $\mathrm{S} 6$ and $\mathrm{S} 7$, which show the activation energy of each polycrystal for $\mathrm{Na}_{3} \mathrm{PS}_{4}$ and $\mathrm{Na}_{3} \mathrm{PO}_{4}$, respectively.
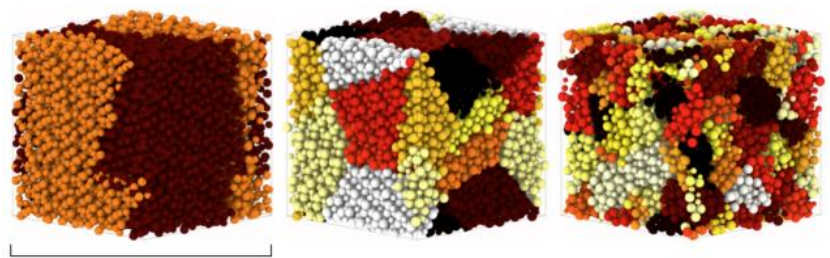

$85 \mathrm{~nm}$

Figure 10. Polycrystals of $\mathrm{Na}_{3} \mathrm{PS}_{4}$ containing (a) 2, (b) 10 and (c) 100 grains (equivalent to grain volumes of 108, 21.6 and $2.16 \mathrm{~nm}^{3}$, respectively). Each color represents a unique grain.

\section{ASSOCIATED CONTENT}

The Supporting Information is available free of charge on the ACS Publications website.

(A) Potential model for $\mathrm{Na}_{3} \mathrm{PS}_{4}$; (B) Potential model for $\mathrm{Na}_{3} \mathrm{PO}_{4}$; (C) MD simulation procedure for polycrystals; (D) Activation energies; (E) Na-ion diffusion and conductivity; (F) $\mathrm{PS}_{4}$ and $\mathrm{PO}_{4}$ orientations; $(\mathrm{G})$ Influence of $\mathrm{Na}$ vacancy concentration.

\section{AUTHOR INFORMATION}

\section{Corresponding Author}

*E-mail: j.a.dawson@bath.ac.uk.

*E-mail: m.s.islam@bath.ac.uk.

\section{Present Addresses}

"Department of Materials Science and Engineering, National University of Singapore, Singapore.

\section{ACKNOWLEDGMENTS}

The authors gratefully acknowledge the EPSRC Programme Grant "Enabling next generation lithium batteries" (EP/Moo9521/1) and the MCC/Archer consortium (EP/Looo202/1).

\section{REFERENCES}

(1) Bachman, J. C.; Muy, S.; Grimaud, A.; Chang, H.-H.; Pour, N.; Lux, S. F.; Paschos, O.; Maglia, F.; Lupart, S.; Lamp, P.; et al. Inorganic Solid-State Electrolytes for Lithium Batteries: Mechanisms and Properties Governing Ion Conduction. Chem. Rev. 2016, 116, 140-162.

(2) Tikekar, M. D.; Choudhury, S.; Tu, Z.; Archer, L. A. Design Principles for Electrolytes and Interfaces for Stable LithiumMetal Batteries. Nat. Energy 2016, 1, 16114.

(3) Janek, J.; Zeier, W. G. A Solid Future for Battery Development. Nat. Energy 2016, 1, 16141.

(4) Manthiram, A.; Yu, X.; Wang, S. Lithium Battery Chemistries Enabled by Solid-State Electrolytes. Nat. Rev. Mater. 2017, 2, 16103.

(5) Kim, J.-J.; Yoon, K.; Park, I.; Kang, K. Progress in the Development of Sodium-Ion Solid Electrolytes. Small Methods 2017, 1, 1700219.

(6) Kamaya, N.; Homma, K.; Yamakawa, Y.; Hirayama, M.; 
Kanno, R.; Yonemura, M.; Kamiyama, T.; Kato, Y.; Hama, S.; Kawamoto, K.; et al. A Lithium Superionic Conductor. Nat. Mater. 2011, 10, 682-686.

(7) Wang, Y.; Richards, W. D.; Ong, S. P.; Miara, L. J.; Kim, J. C.; Mo, Y.; Ceder, G. Design Principles for Solid-State Lithium Superionic Conductors. Nat. Mater. 2015, 14, 1026-1031.

Zhonghui, G.; Huabin, S.; Lin, F.; Fangliang, Y.; Yi, Z.; Wei, L.; Yunhui, H. Promises, Challenges, and Recent Progress of Inorganic Solid-State Electrolytes for All-Solid-State Lithium Batteries. Adv. Mater. 2018, 30, 1705702.

(9) Chenglong, Z.; Lilu, L.; Xingguo, Q.; Yaxiang, L.; Feixiang, W.; Junmei, Z.; Yan, Y.; Yong-Sheng, H.; Liquan, C. SolidState Sodium Batteries. Adv. Energy Mater. 2018, 8, 1703012.

(10) Inoue, T.; Mukai, K. Are All-Solid-State Lithium-Ion Batteries Really Safe?-Verification by Differential Scanning Calorimetry with an All-Inclusive Microcell. ACS Appl. Mater. Interfaces 2017, 9, 1507-1515.

(11) Goodenough, J. B.; Hong, H. .-P.; Kafalas, J. A. Fast Na+-Ion Transport in Skeleton Structures. Mater. Res. Bull. 1976, 11, 203-220.

(12) Bruce, P. G.; West, A. R. The A-C Conductivity of Polycrystalline LISICON, $\mathrm{Li}_{2+2 x} \mathrm{Zn}_{1-x} \mathrm{GeO}_{4}$, and a Model for Intergranular Constriction Resistances. J. Electrochem. Soc. 1983, 130, 662-669.

(13) Kanno, R.; Hata, T.; Kawamoto, Y.; Irie, M. Synthesis of a New Lithium Ionic Conductor, Thio-LISICON-Lithium Germanium Sulfide System. Solid State Ionics 20oo, 130, 97104

(14) Murugan, R.; Thangadurai, V.; Weppner, W. Fast Lithium Ion Conduction in Garnet-Type $\mathrm{Li}_{7} \mathrm{La}_{3} \mathrm{Zr}_{2} \mathrm{O}_{12}$. Angew. Chemie Int. Ed. 2007, 46, 7778-7781.

(15) Dawson, J. A.; Attari, T. S.; Chen, H.; Emge, S. P.; Johnston, K. E.; Islam, M. S. Elucidating Lithium-Ion and Proton Dynamics in Anti-Perovskite Solid Electrolytes. Energy Environ. Sci. 2018, 11, 2993-3002.

(16) Dawson, J. A.; Canepa, P.; Famprikis, T.; Masquelier, C.; Islam, M. S. Atomic-Scale Influence of Grain Boundaries on Li-Ion Conduction in Solid Electrolytes for All-Solid-State Batteries. J. Am. Chem. Soc. 2018, 140, 362-368.

(17) Canepa, P.; Dawson, J. A.; Sai Gautam, G.; Statham, J. M. Parker, S. C.; Islam, M. S. Particle Morphology and Lithium Segregation to Surfaces of the $\mathrm{Li}_{7} \mathrm{La}_{3} \mathrm{Zr}_{2} \mathrm{O}_{12}$ Solid Electrolyte. Chem. Mater. 2018, 30, 3019-3027.

(18) Yu, C.; Ganapathy, S.; de Klerk, N. J. J.; Roslon, I.; van Eck, E. R. H.; Kentgens, A. P. M.; Wagemaker, M. Unravelling Li-Ion Transport from Picoseconds to Seconds: Bulk versus Interfaces in an Argyrodite $\mathrm{Li}_{6} \mathrm{PS}_{5} \mathrm{Cl}-\mathrm{Li}_{2} \mathrm{~S}$ All-Solid-State LiIon Battery. J. Am. Chem. Soc. 2016, 138, 11192-11201.

(19) Kato, Y.; Hori, S.; Saito, T.; Suzuki, K.; Hirayama, M.; Mitsui, A.; Yonemura, M.; Iba, H.; Kanno, R. High-Power All-SolidState Batteries Using Sulfide Superionic Conductors. Nat. Energy 2016, 1, 16030.

(20) Kuhn, A.; Duppel, V.; Lotsch, B. V. Tetragonal $\mathrm{Li}_{10} \mathrm{GeP}_{2} \mathrm{~S}_{12}$ and $\mathrm{Li}_{7} \mathrm{GePS}_{8}$ - Exploring the Li Ion Dynamics in LGPS Li Electrolytes. Energy Environ. Sci. 2013, 6, 3548-3552.

(21) Krauskopf, T.; Culver, S. P.; Zeier, W. G. Local Tetragonal Structure of the Cubic Superionic Conductor $\mathrm{Na}_{3} \mathrm{PS}_{4}$. Inorg. Chem. 2018, 57, 4739-4744.

(22) Lepley, N. D.; Holzwarth, N. A. W.; Du, Y. A. Structures, Li ${ }^{+}$ Mobilities, and Interfacial Properties of Solid Electrolytes $\mathrm{Li}_{3} \mathrm{PS}_{4}$ and $\mathrm{Li}_{3} \mathrm{PO}_{4}$ from First Principles. Phys. Rev. B 2013, 88, 104103.

(23) Zhang, Z.; Ramos, E.; Lalère, F.; Assoud, A.; Kaup, K.; Hartman, P.; Nazar, L. F. $\mathrm{Na}_{11} \mathrm{Sn}_{2} \mathrm{PS}_{12}$ : A New Solid State Sodium Superionic Conductor. Energy Environ. Sci. 2018, 11, 87-93.

(24) Kudu, Ö. U.; Famprikis, T.; Fleutot, B.; Braida, M.-D.; Le Mercier, T.; Islam, M. S.; Masquelier, C. A Review of Structural Properties and Synthesis Methods of Solid Electrolyte Materials in the $\mathrm{Li}_{2} \mathrm{~S}-\mathrm{P}_{2} \mathrm{~S}_{5}$ Binary System. J. Power Sources 2018, 407, 31-43.
(25) Hayashi, A.; Sakuda, A.; Tatsumisago, M. Development of Sulfide Solid Electrolytes and Interface Formation Processes for Bulk-Type All-Solid-State Li and Na Batteries. Front. Energy Res. 2016, 4, 25.

(26) Hayashi, A.; Noi, K.; Sakuda, A.; Tatsumisago, M. Superionic Glass-Ceramic Electrolytes for Room-Temperature Rechargeable Sodium Batteries. Nat. Commun. 2012, 3, 856.

(27) Yu, C.; Ganapathy, S.; de Klerk, N. J. J.; van Eck, E. R. H.; Wagemaker, M. Na-Ion Dynamics in Tetragonal and Cubic $\mathrm{Na}_{3} \mathrm{PS}_{4}$, a Na-Ion Conductor for Solid State Na-Ion Batteries. J. Mater. Chem. A 2016, 4, 15095-15105.

(28) Duchardt, M.; Ruschewitz, U.; Adams, S.; Dehnen, S.; Roling, B. Vacancy-Controlled $\mathrm{Na}^{+}$Superion Conduction in $\mathrm{Na}_{11} \mathrm{Sn}_{2} \mathrm{PS}_{12}$. Angew. Chemie Int. Ed. 2017, 57, 1351-1355.

(29) Bron, P.; Dehnen, S.; Roling, B. $\mathrm{Li}_{10} \mathrm{Si}_{\mathrm{o} .3} \mathrm{Sn}_{0.7} \mathrm{P}_{2} \mathrm{~S}_{12}-$ A Low-Cost and Low-Grain-Boundary-Resistance Lithium Superionic Conductor. J. Power Sources 2016, 329, 530-535.

(30) Hori, S.; Suzuki, K.; Hirayama, M.; Kato, Y.; Kanno, R. Lithium Superionic Conductor $\mathrm{Li}_{9.42} \mathrm{Si}_{1.02} \mathrm{P}_{2.1} \mathrm{~S}_{9.96} \mathrm{O}_{2.04}$ with $\mathrm{Li}_{10} \mathrm{GeP}_{2} \mathrm{~S}_{12}$-Type Structure in the $\mathrm{Li}_{2} \mathrm{~S}-\mathrm{P}_{2} \mathrm{~S}_{5}-\mathrm{SiO}_{2}$ Pseudoternary System: Synthesis, Electrochemical Properties, and Structure-Composition Relationships. Front. Energy Res. 2016, 4, 38.

(31) Sakuda, A.; Hayashi, A.; Tatsumisago, M. Sulfide Solid Electrolyte with Favorable Mechanical Property for AllSolid-State Lithium Battery. Sci. Rep. 2013, 3, 2261.

(32) Tatsumisago, M.; Nagao, M.; Hayashi, A. Recent Development of Sulfide Solid Electrolytes and Interfacial Modification for All-Solid-State Rechargeable Lithium Batteries. J. Asian Ceram. Soc. 2013, 1, 17-25.

(33) Raj, R.; Wolfenstine, J. Current Limit Diagrams for Dendrite Formation in Solid-State Electrolytes for Li-Ion Batteries. J. Power Sources 2017, 343, 119-126.

(34) Shen, F.; Dixit, M. B.; Xiao, X.; Hatzell, K. B. Effect of Pore Connectivity on Li Dendrite Propagation within LLZO Electrolytes Observed with Synchrotron X-Ray Tomography. ACS Energy Lett. 2018, 3, 1056-1061.

(35) Porz, L.; Swamy, T.; Sheldon, B. W.; Rettenwander, D.; Frömling, T.; Thaman, H. L.; Berendts, S.; Uecker, R.; Carter, W. C.; Chiang, Y.-M. Mechanism of Lithium Metal Penetration through Inorganic Solid Electrolytes. Adv. Energy Mater. 2017, 7, 1701003.

(36) Stegmaier, S.; Voss, J.; Reuter, K.; Luntz, A. C. Li ${ }^{+}$Defects in a Solid-State Li Ion Battery: Theoretical Insights with a $\mathrm{Li}_{3} \mathrm{OCl}$ Electrolyte. Chem. Mater. 2017, 29, 4330-4340.

（37） Liu, Z.; Fu, W.; Payzant, E. A.; Yu, X.; Wu, Z.; Dudney, N. J.; Kiggans, J.; Hong, K.; Rondinone, A. J.; Liang, C. Anomalous High Ionic Conductivity of Nanoporous $\beta-\mathrm{Li}_{3} \mathrm{PS}_{4}$. J. Am. Chem. Soc. 2013, 135, 975-978.

(38) Tsukasaki, H.; Mori, S.; Morimoto, H.; Hayashi, A.; Tatsumisago, M. Direct Observation of a Non-Crystalline State of $\mathrm{Li}_{2} \mathrm{~S}-\mathrm{P}_{2} \mathrm{~S}_{5}$ Solid Electrolytes. Sci. Rep. 2017, 7, 4142.

(39) de Klerk, N. J.; Wagemaker, M. Diffusion Mechanism of the Sodium-Ion Solid Electrolyte $\mathrm{Na}_{3} \mathrm{PS}_{4}$ and Potential Improvements of Halogen Doping. Chem. Mater. 2016, 28, 3122-3130.

(40) Krauskopf, T.; Pompe, C.; Kraft, M.; Zeier, W. G. Influence of Lattice Dynamics on $\mathrm{Na}^{+}$-Transport in the Solid Electrolyte $\mathrm{Na}_{3} \mathrm{PS}_{4-\mathrm{x}} \mathrm{Se}_{\mathrm{x}}$. Chem. Mater. 2017, 29, 8859-8869.

(41) Nishimura, S.; Tanibata, N.; Hayashi, A.; Tatsumisago, M.; Yamada, A. The Crystal Structure and Sodium Disorder of High-Temperature Polymorph $\beta-\mathrm{Na}_{3} \mathrm{PS}_{4}$. J. Mater. Chem. A 2017, 5, 25025-25030.

(42) Chu, I.-H.; Kompella, C. S.; Nguyen, H.; Zhu, Z.; Hy, S.; Deng, Z.; Meng, Y. S.; Ong, S. P. Room-Temperature All-Solid-State Rechargeable Sodium-Ion Batteries with a Cl-Doped $\mathrm{Na}_{3} \mathrm{PS}_{4}$ Superionic Conductor. Sci. Rep. 2016, 6, 33733.

(43) Tanibata, N.; Noi, K.; Hayashi, A.; Tatsumisago, M. Preparation and Characterization of Highly Sodium Ion Conducting $\mathrm{Na}_{3} \mathrm{PS}_{4}-\mathrm{Na}_{4} \mathrm{SiS}_{4}$ Solid Electrolytes. RSC Adv. 2014, 4, 17120-17123. 
Moon, C. K.; Lee, H.-J.; Park, K. H.; Kwak, H.; Heo, J. W.; Choi, K.; Yang, H.; Kim, M.-S.; Hong, S.-T.; Lee, J. H.; et al. Vacancy-Driven $\mathrm{Na}^{+}$Superionic Conduction in New CaDoped $\mathrm{Na}_{3} \mathrm{PS}_{4}$ for All-Solid-State Na-Ion Batteries. ACS Energy Lett. 2018, 2504-2512.

(45) Zhu, Z.; Chu, I.-H.; Deng, Z.; Ong, S. P. Role of Na+ Interstitials and Dopants in Enhancing the $\mathrm{Na}+$ Conductivity of the Cubic $\mathrm{Na}_{3} \mathrm{PS}_{4}$ Superionic Conductor. Chem. Mater. 2015, 27, 8318-8325.

(46) Krauskopf, T.; Muy, S.; Culver, S. P.; Ohno, S.; Delaire, O.; Shao-Horn, Y.; Zeier, W. G. Comparing the Descriptors for Investigating the Influence of Lattice Dynamics on Ionic Transport Using the Superionic Conductor $\mathrm{Na}_{3} \mathrm{PS}_{4-\mathrm{X}} \mathrm{Se}_{\mathrm{x}}$. J. Am. Chem. Soc. 2018, 140, 14464-14473.

(47) Famprikis, T.; Dawson, J.A.; Fauth, F.; Suard, E.; Fleutot, B.; Courty, M.; Chotard, J.-N.; Islam, S.; Masquelier, C. A New Phase of the $\mathrm{Na}^{+}$Ion Conductor $\mathrm{Na}_{3} \mathrm{PS}_{4}$. 2019, ChemRxiv, DOI: $10.26434 /$ chemrxiv.8003717.

(48) Hayashi, A.; Noi, K.; Tanibata, N.; Nagao, M.; Tatsumisago, M. High Sodium Ion Conductivity of Glass-Ceramic Electrolytes with Cubic $\mathrm{Na}_{3} \mathrm{PS}_{4}$. J. Power Sources 2014, 258, 420-423.

(49) Yu, C.; Ganapathy, S.; van Eck, E. R. H.; van Eijck, L.; Basak, S.; Liu, Y.; Zhang, L.; Zandbergen, H. W.; Wagemaker, M. Revealing the Relation between the Structure, Li-Ion Conductivity and Solid-State Battery Performance of the Argyrodite $\mathrm{Li}_{6} \mathrm{PS}_{5} \mathrm{Br}$ Solid Electrolyte. J. Mater. Chem. A 2017, 5, 21178-21188.

(50) Sun, Y.; Suzuki, K.; Hori, S.; Hirayama, M.; Kanno, R. Superionic Conductors: $\mathrm{Li}_{10+\delta}\left[\mathrm{Sn}_{\mathrm{y}} \mathrm{Si}_{1-y}\right]_{1+\delta} \mathrm{P}_{2-\delta} \mathrm{S}_{12}$ with a $\mathrm{Li}_{10} \mathrm{GeP}_{2} \mathrm{~S}_{12}$-Type Structure in the $\mathrm{Li}_{3} \mathrm{PS}_{4}-\mathrm{Li}_{4} \mathrm{SnS}_{4}-\mathrm{Li}_{4} \mathrm{SiS}_{4}$ Quasi-Ternary System. Chem. Mater. 2017, 29, 5858-5864.

(51) Hooper, A.; McGeehin, P.; Harrison, K. T.; Tofield, B. C. Ionic Conductivity of Pure and Doped $\mathrm{Na}_{3} \mathrm{PO}_{4}$. J. Solid State Chem. 1978, 24, 265-275.

(52) Hruschka, H.; Lissel, E.; Jansen, M. Na-Ion Conduction in the Solid Solutions of $\mathrm{Na}_{3} \mathrm{PO}_{4} / \mathrm{Na}_{2} \mathrm{SO}_{4}$ and $\mathrm{Na}_{3} \mathrm{AlF}_{6} / \mathrm{Na}_{2} \mathrm{SO}_{4}$. Solid State Ionics 1988, 28-30, 159-162.

(53) Yin, W.-G.; Liu, J.; Duan, C.-G.; Mei, W. N.; Smith, R. W.; Hardy, J. R. Superionicity in $\mathrm{Na}_{3} \mathrm{PO}_{4}$ : A Molecular Dynamics Simulation. Phys. Rev. B 2004, 70, 64302.

(54) Jansen, M.; Henseler, U. Synthesis, Structure Determination, and Ionic Conductivity of Sodium Tetrathiophosphate. J. Solid State Chem. 1992, 99, 110-119.

(55) Harrison, R. J.; Putnis, A.; Kockelmann, W. Phase Transition Behaviour and Equilibrium Phase Relations in the Fast-Ion Conductor System $\mathrm{Na}_{3} \mathrm{PO}_{4}-\mathrm{Na}_{2} \mathrm{SO}_{4}$. Phys. Chem. Chem. Phys. 2002, 4, 3252-3259.

(56) Pompetzki, M.; Dinnebier, R. E.; Jansen, M. Sodium Dithiophosphate(V): Crystal Structure, Sodium Ionic Conductivity and Dismutation. Solid State Sci. 2003, 5, 14391444 .

(57) Yu, S.; Siegel, D. J. Grain Boundary Contributions to Li-Ion Transport in the Solid Electrolyte $\mathrm{Li}_{7} \mathrm{La}_{3} \mathrm{Zr}_{2} \mathrm{O}_{12}$ (LLZO). Chem. Mater. 2017, 29, 9639-9647.

(58) Ma, C.; Chen, K.; Liang, C.; Nan, C.-W.; Ishikawa, R.; More, K.; Chi, M. Atomic-Scale Origin of the Large Grain-Boundary Resistance in Perovskite Li-Ion-Conducting Solid Electrolytes. Energy Environ. Sci. 2014, 7, 1638-1642.

(59) Park, H.; Jung, K.; Nezafati, M.; Kim, C.-S.; Kang, B. Sodium Ion Diffusion in Nasicon $\left(\mathrm{Na}_{3} \mathrm{Zr}_{2} \mathrm{Si}_{2} \mathrm{PO}_{12}\right)$ Solid Electrolytes: Effects of Excess Sodium. ACS Appl. Mater. Interfaces 2016, $8,27814-27824$.

(6o) Huang, H.; Wu, H.-H.; Wang, X.; Huang, B.; Zhang, T.-Y. Enhancing Sodium Ionic Conductivity in Tetragonal- $\mathrm{Na}_{3} \mathrm{PS}_{4}$ by Halogen Doping: A First Principles Investigation. Phys. Chem. Chem. Phys. 2018, 20, 20525-20533.

(61) Wilmer, D.; Funke, K.; Witschas, M.; Banhatti, R. D.; Jansen, M.; Korus, G.; Fitter, J.; Lechner, R. E. Anion Reorientation in an Ion Conducting Plastic Crystal - Coherent Quasielastic Neutron Scattering from Sodium Ortho-Phosphate. Phys. B
Condens. Matter 1999, 266, 60-68.

(62) Deng, Y.; Eames, C.; Chotard, J.-N.; Lalère, F.; Seznec, V.; Emge, S.; Pecher, O.; Grey, C. P.; Masquelier, C.; Islam, M. S. Structural and Mechanistic Insights into Fast Lithium-Ion Conduction in $\mathrm{Li}_{4} \mathrm{SiO}_{4}-\mathrm{Li}_{3} \mathrm{PO}_{4}$ Solid Electrolytes. J. Am. Chem. Soc. 2015, 137, 9136-9145.

(63) Heitjans, P.; Kärger, J. Diffusion in Condensed Matter: Methods, Materials, Models. Springer Berlin Heidelberg, Berlin, Heidelberg, 2005.

(64) Islam, M. S.; Fisher, C. A. J. Lithium and Sodium Battery Cathode Materials: Computational Insights into Voltage, Diffusion and Nanostructural Properties. Chem. Soc. Rev. 2014, 43, 185-204.

(65) Muralidharan, A.; Chaudhari, M. I.; Pratt, L. R.; Rempe, S. B. Molecular Dynamics of Lithium Ion Transport in a Model Solid Electrolyte Interphase. Sci. Rep. 2018, 8, 10736.

(66) de Klerk, N. J. J.; van der Maas, E.; Wagemaker, M. Analysis of Diffusion in Solid-State Electrolytes through MD Simulations, Improvement of the Li-Ion Conductivity in $\beta$ $\mathrm{Li}_{3} \mathrm{PS}_{4}$ as an Example. ACS Appl. Energy Mater. 2018, 1, 32303242.

(67) Dawson, J. A.; Chen, H.; Islam, M. S. Composition Screening of Lithium- and Sodium-Rich Anti-Perovskites for FastConducting Solid Electrolytes. J. Phys. Chem. C 2018, 122, 23978-23984

(68) Aparicio, P. A.; Dawson, J. A.; Islam, M. S.; de Leeuw, N. H. Computational Study of $\mathrm{NaVOPO}_{4}$ Polymorphs as Cathode Materials for Na-Ion Batteries: Diffusion, Electronic Properties, and Cation-Doping Behavior. J. Phys. Chem. C 2018, 122, 25829-25836.

(69) Gale, J. D.; Rohl, A. L. The General Utility Lattice Program (GULP). Mol. Simul. 2003, 29, 291-341.

(70) Tilocca, A.; Cormack, A. N.; de Leeuw, N. H. The Structure of Bioactive Silicate Glasses: New Insight from Molecular Dynamics Simulations. Chem. Mater. 2007, 19, 95-103.

(71) Harding, J. H.

http://www.ucl.ac.uk/klmc/Potentials/Library/diller.lib (accessed Nov 12, 2018).

(72) Plimpton, S. Fast Parallel Algorithms for Short-Range Molecular Dynamics. J. Comput. Phys. 1995, 117, 1-19.

(73) Evans, D. J. The Nose-Hoover Thermostat. J. Chem. Phys. 1985, 83, 4069-4074.

(74) Hirel, P. Atomsk: A Tool for Manipulating and Converting Atomic Data Files. Comput. Phys. Commun. 2015, 197, 212219. 


\title{
-Supporting Information-
}

\section{Towards Understanding the Different Influences of Grain Boundaries on Ion Transport in Sulfide and Oxide Solid Electrolytes}

\author{
James A. Dawson, ${ }^{\dagger *}$ Pieremanuele Canepa,${ }^{\dagger}$ Matthew J. Clarke, ${ }^{\dagger}$ Theodosios Famprikis, ${ }^{\dagger}$ \\ Dibyajyoti Ghosh $^{\dagger}$ and M. Saiful Islam ${ }^{\dagger *}$ \\ †Department of Chemistry, University of Bath, Bath, BA2 7AY, UK \\ ${ }^{\ddagger}$ Laboratoire de Réactivité et de Chimie des Solides (UMR CNRS 7314), Université de \\ Picardie Jules Verne, 33 rue Saint Leu, 80039 Amiens Cedex, France
}

\section{(A) Potential model for $\mathrm{Na}_{3} \mathrm{PS}_{4}$}

Given the lack of classical molecular dynamics studies of $\mathrm{Na}_{3} \mathrm{PS}_{4}$ in the literature, it was necessary to derive a new interatomic potential model. The fitting procedure was carried out using the General Utility Lattice Program (GULP). ${ }^{1}$ The potential model was fit to the cubic $\mathrm{Na}_{3} \mathrm{PS}_{4}$ structure with a lattice parameter of $a=6.989 \AA$ derived from X-ray diffraction. ${ }^{2}$ As a starting point, we used the Na-Na, Na-S and S-S Buckingham potentials of Harding, which were originally derived for $\mathrm{Na}_{2} \mathrm{~S}^{3}{ }^{3}$ These potentials were optimized for the $\mathrm{Na}_{3} \mathrm{PS}_{4}$ structure and an entirely new P-S Buckingham potential was created. The potential model parameters used for $\mathrm{Na}_{3} \mathrm{PS}_{4}$ throughout this work are listed in Table S1. The derived potential model was stable during geometry optimization and the calculated lattice parameter of $6.992 \AA$ is in excellent agreement with experiment. The validity of the potential is also indicated by the marginal differences between the computed and experimental bond distances, as shown in Table S2. Furthermore, as described in the manuscript, the calculated radial distribution functions are in excellent agreement with previous ab initio molecular dynamics calculations. ${ }^{4}$ 
Table S1. Buckingham potential $\left(\left(A \exp (-\rho / \mathrm{r})-\mathrm{C} / \mathrm{r}^{6}\right)\right)$ parameters for Na33S4.

\begin{tabular}{|l|c|c|c|}
\hline Interaction & $A(\mathrm{eV})$ & $\rho(\AA)$ & $C\left(\mathrm{eV}^{6}\right)$ \\
\hline $\mathrm{Na}^{+}-\mathrm{Na}^{+}$ & 7890.32 & 0.168 & 0.10 \\
\hline $\mathrm{Na}^{+}-\mathrm{S}^{2-}$ & 508.785 & 0.367 & 0.10 \\
\hline $\mathrm{P}^{5+}-\mathrm{S}^{2-}$ & 2411.36 & 0.347 & 0.10 \\
\hline $\mathrm{S}^{2-}-\mathrm{S}^{2-}$ & 5379.166 & 0.40 & 1229.531 \\
\hline
\end{tabular}

Table S2. Comparison of calculated and experimental bond distances $(\AA)$ for $\mathrm{Na}_{3} \mathrm{PS}_{4}$.

\begin{tabular}{|l|c|c|c|c|c|}
\hline & $\mathrm{Na}-\mathrm{Na}$ & $\mathrm{Na}-\mathrm{P}$ & $\mathrm{Na}-\mathrm{S}$ & $\mathrm{P}-\mathrm{S}$ & $\mathrm{S}-\mathrm{S}$ \\
\hline This work & 3.496 & 3.496 & 2.858 & 2.069 & 3.369 \\
\hline X-ray diffraction $^{2}$ & 3.495 & 3.495 & 2.853 & 2.024 & 3.305 \\
\hline
\end{tabular}

\section{(B) Potential model for $\mathrm{Na}_{3} \mathrm{PO}_{4}$}

For the simulation of $\mathrm{Na}_{3} \mathrm{PO}_{4}$, we used the proven potential model of Tilocca et al. ${ }^{5}$ that was developed for molecular dynamics calculations of phosphosilicate glasses. This model was also augmented with the $\mathrm{Na}-\mathrm{Na}$ interatomic potential from $\mathrm{Harding}^{3}$ for consistency with the $\mathrm{Na}_{3} \mathrm{PS}_{4}$ model. The potential model parameters used for $\mathrm{Na}_{3} \mathrm{PO}_{4}$ in this work are listed in Table S3. The calculated and experimental lattice parameters of 7.524 and $7.544 \AA$, respectively, are in excellent agreement. The computed and experimental bond distances are compared in Table S4.

Table S3. Buckingham potential $\left(\left(A \exp (-\rho / \mathrm{r})-\mathrm{C} / \mathrm{r}^{6}\right)\right)$ parameters for $\mathrm{Na}_{3} \mathrm{PO}_{4}$ taken from Tilocca et al. ${ }^{5}$ and Harding. ${ }^{3}$

\begin{tabular}{|l|c|c|c|}
\hline Interaction & $A(\mathrm{eV})$ & $\rho(\AA)$ & $C\left(\mathrm{eV}^{6}\right)$ \\
\hline $\mathrm{Na}^{+}-\mathrm{Na}^{+}$ & 7895.4 & 0.171 & 0.0 \\
\hline $\mathrm{Na}^{+}-\mathrm{O}^{2-}$ & 56465.345 & 0.194 & 0.0 \\
\hline $\mathrm{P}^{5+}-\mathrm{O}^{2-}$ & 1120.091 & 0.335 & 0.0 \\
\hline $\mathrm{O}^{2-}-\mathrm{O}^{2-}$ & 22764.0 & 0.149 & 27.88 \\
\hline
\end{tabular}


Table S4. Comparison of calculated and experimental bond distances $(\AA)$ for $\mathrm{Na}_{3} \mathrm{PO}_{4}$.

\begin{tabular}{|l|c|c|c|c|c|}
\hline & $\mathrm{Na}-\mathrm{Na}$ & $\mathrm{Na}-\mathrm{P}$ & $\mathrm{Na}-\mathrm{O}$ & $\mathrm{P}-\mathrm{O}$ & $\mathrm{O}-\mathrm{O}$ \\
\hline This work & 3.258 & 3.258 & 2.175 & 1.434 & 2.028 \\
\hline Neutron diffraction $^{6}$ & 3.267 & 3.267 & $1.910 / 2.263$ & 1.443 & 2.112 \\
\hline
\end{tabular}

\section{(C) MD simulation procedure for polycrystals}

Table S5. Average stoichiometries of $\mathrm{Na}_{3} \mathrm{PS}_{4}$ and $\mathrm{Na}_{3} \mathrm{PO}_{4}$ polycrystals.

\begin{tabular}{|l|c|}
\hline Grain volume $\left(\mathrm{nm}^{3}\right)$ & Average stoichiometry \\
\hline $\mathrm{Na}_{3} \mathrm{PS}_{4}-108$ & $\mathrm{Na}_{3.20} \mathrm{P}_{1.04} \mathrm{~S}_{4.20}$ \\
\hline $\mathrm{Na}_{3} \mathrm{PS}_{4}-43.2$ & $\mathrm{Na}_{2.95} \mathrm{P}_{0.99} \mathrm{~S}_{3.95}$ \\
\hline $\mathrm{Na}_{3} \mathrm{PS}_{4}-21.6$ & $\mathrm{Na}_{2.92} \mathrm{P}_{0.97} \mathrm{~S}_{3.89}$ \\
\hline $\mathrm{Na}_{3} \mathrm{PS}_{4}-10.8$ & $\mathrm{Na}_{2.90} \mathrm{P}_{0.96} \mathrm{~S}_{3.85}$ \\
\hline $\mathrm{Na}_{3} \mathrm{PS}_{4}-2.16$ & $\mathrm{Na}_{2.85} \mathrm{P}_{0.94} \mathrm{~S}_{3.78}$ \\
\hline $\mathrm{Na}_{3} \mathrm{PO}_{4}-108$ & $\mathrm{Na}_{3 .}{ }_{09} \mathrm{P}_{1.03} \mathrm{O}_{4.12}$ \\
\hline $\mathrm{Na}_{3} \mathrm{PO}_{4}-43.2$ & $\mathrm{Na}_{2.97} \mathrm{P}_{0.99} \mathrm{O}_{3.96}$ \\
\hline $\mathrm{Na}_{3} \mathrm{PO}_{4}-21.6$ & $\mathrm{Na}_{2.96} \mathrm{P}_{0.98} \mathrm{O}_{3.93}$ \\
\hline $\mathrm{Na}_{3} \mathrm{PO}_{4}-10.8$ & $\mathrm{Na}_{2 .}{ }_{22} \mathrm{P}_{0.95} \mathrm{O}_{3.84}$ \\
\hline $\mathrm{Na}_{3} \mathrm{PO}_{4}-2.16$ & $\mathrm{Na}_{2.85} \mathrm{P}_{0.93} \mathrm{O}_{3.75}$ \\
\hline
\end{tabular}

After the construction of the polycrystals, many ions are located in close proximity to each other at the GBs. Therefore, before the MD simulations, ions with interatomic distances of less than $1.5 \AA$ to their neighbours were removed. Any charge imbalance resulting from this removal process was neutralized by the creation of additional vacancies. The number of ions removed was proportional to the number of grains/GBs in the polycrystals, i.e., the smaller the grain volume, the lower the number of ions in the cell, as can be seen in Table S5. This trend is true for both $\mathrm{Na}_{3} \mathrm{PS}_{4}$ and $\mathrm{Na}_{3} \mathrm{PO}_{4}$, and is not expected to significantly affect the results. 


\section{(D) Activation energies}

Table S6. Calculated activation energy $\left(E_{\mathrm{a}}, \mathrm{meV}\right)$ of each $\mathrm{Na}_{3} \mathrm{PS}_{4}$ polycrystal.

\begin{tabular}{|l|c|}
\hline Grain volume $\left(\mathrm{nm}^{3}\right)$ & $E_{\mathrm{a}}$ \\
\hline $108(1)$ & 297 \\
\hline $108(2)$ & 296 \\
\hline $108(3)$ & 293 \\
\hline $43.2(1)$ & 298 \\
\hline $43.2(2)$ & 291 \\
\hline $43.2(3)$ & 289 \\
\hline $21.6(1)$ & 295 \\
\hline $21.6(2)$ & 296 \\
\hline $21.6(3)$ & 283 \\
\hline $10.8(1)$ & 275 \\
\hline $10.8(2)$ & 270 \\
\hline $10.8(3)$ & 278 \\
\hline $2.16(1)$ & 271 \\
\hline $2.16(2)$ & 282 \\
\hline $2.16(3)$ & 273 \\
\hline
\end{tabular}

Table S7. Calculated activation energy $\left(E_{\mathrm{a}}, \mathrm{meV}\right)$ of each $\mathrm{Na}_{3} \mathrm{PO}_{4}$ polycrystal.

\begin{tabular}{|l|c|}
\hline Grain volume $\left(\mathrm{nm}^{3}\right)$ & $E_{\mathrm{a}}$ \\
\hline $108(1)$ & 359 \\
\hline $108(2)$ & 352 \\
\hline $108(3)$ & 347 \\
\hline $43.2(1)$ & 361 \\
\hline $43.2(2)$ & 367 \\
\hline $43.2(3)$ & 352 \\
\hline $21.6(1)$ & 359 \\
\hline $21.6(2)$ & 357 \\
\hline $21.6(3)$ & 375 \\
\hline $10.8(1)$ & 365 \\
\hline $10.8(2)$ & 367 \\
\hline $10.8(3)$ & 385 \\
\hline $2.16(1)$ & 390 \\
\hline $2.16(2)$ & 391 \\
\hline $2.16(3)$ & 372 \\
\hline
\end{tabular}


(E) Na-ion diffusion and conductivity
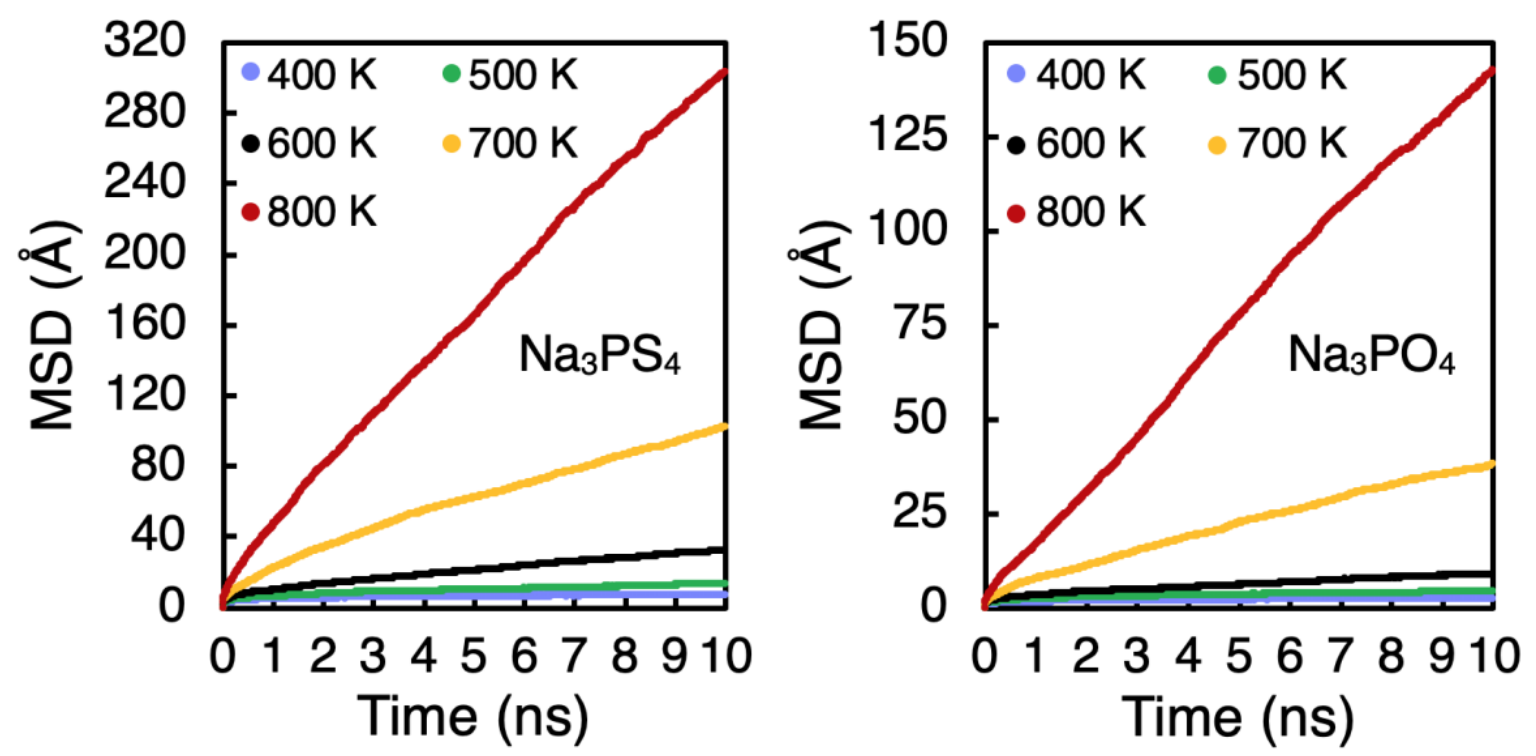

Figure S1. Mean squared displacements for Na-ion diffusion in bulk $\mathrm{Na}_{3} \mathrm{PS}_{4}$ and $\mathrm{Na}_{3} \mathrm{PO}_{4}$.
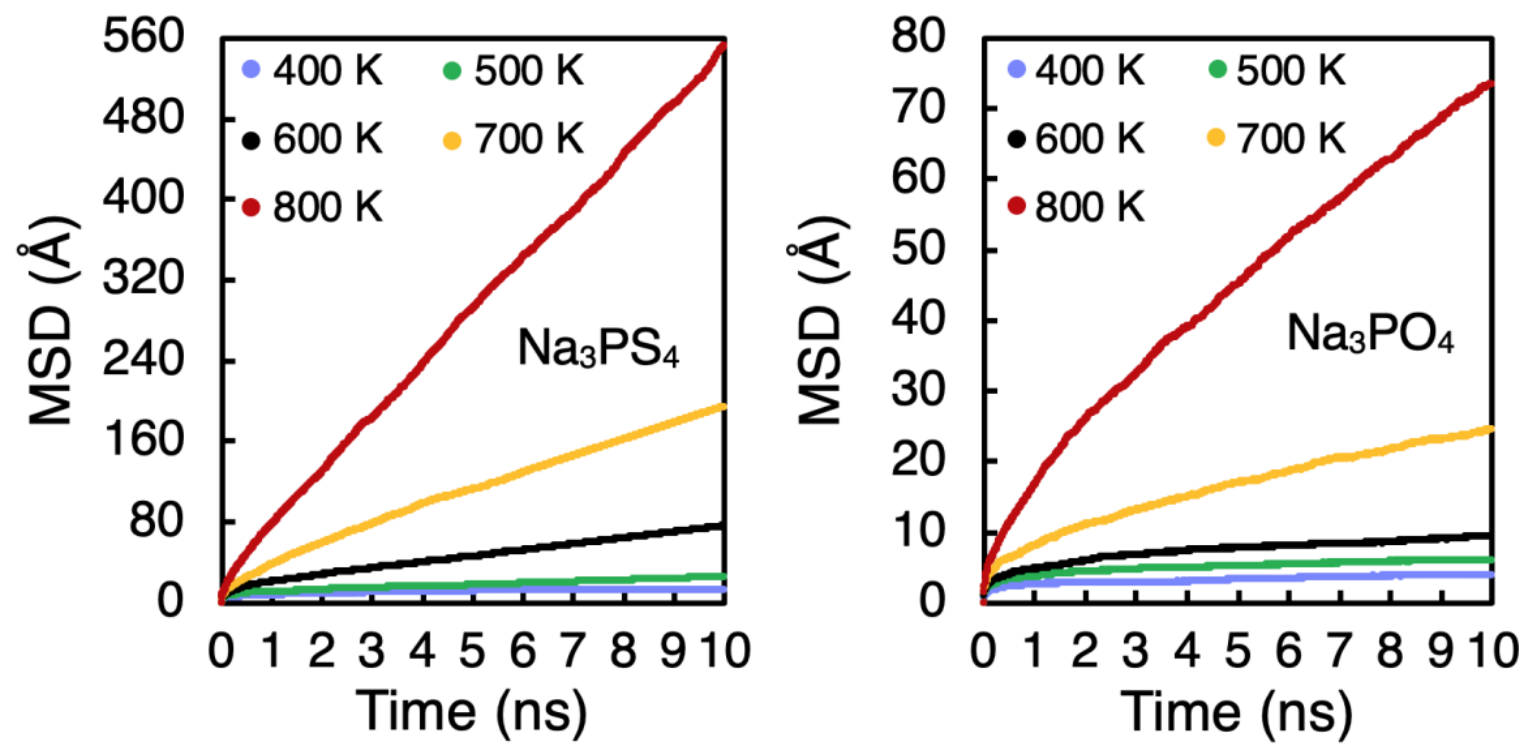

Figure S2. Example mean squared displacements for Na-ion diffusion in polycrystalline (grain volume of $2.16 \mathrm{~nm}^{3}$ ) $\mathrm{Na}_{3} \mathrm{PS}_{4}$ and $\mathrm{Na}_{3} \mathrm{PO}_{4}$. 
$\mathrm{T}\left({ }^{\circ} \mathrm{C}\right)$

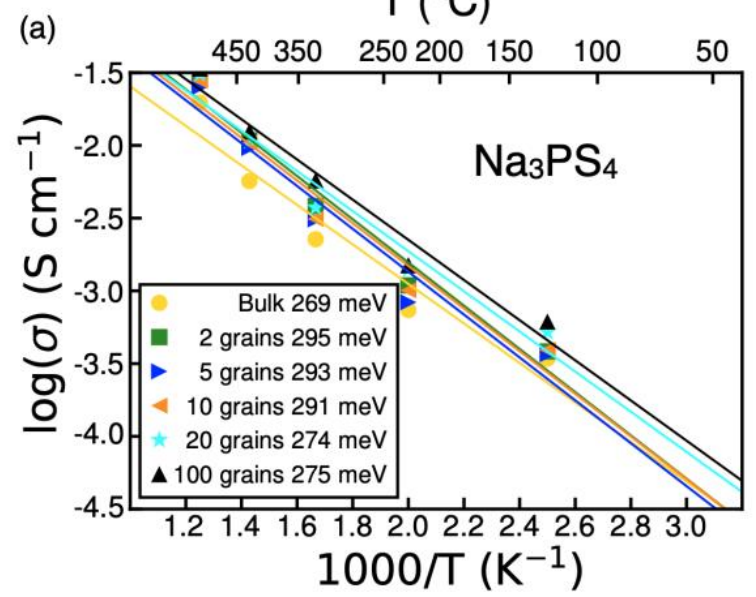

$\mathrm{T}\left({ }^{\circ} \mathrm{C}\right)$

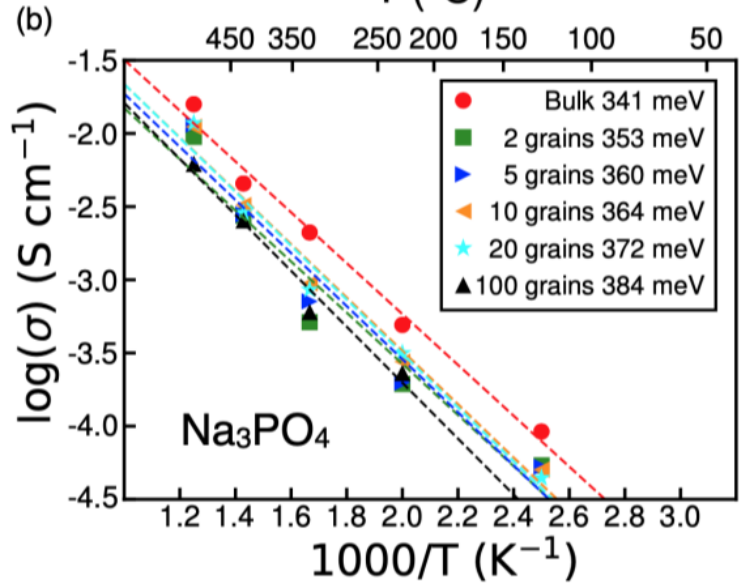

Figure S3. Na-ion conductivities $(\sigma)$ and activation energies $\left(E_{\mathrm{a}}\right)$ for bulk and polycrystalline $\mathrm{Na}_{3} \mathrm{PS}_{4}$ and $\mathrm{Na}_{3} \mathrm{PO}_{4}$. 
(a)

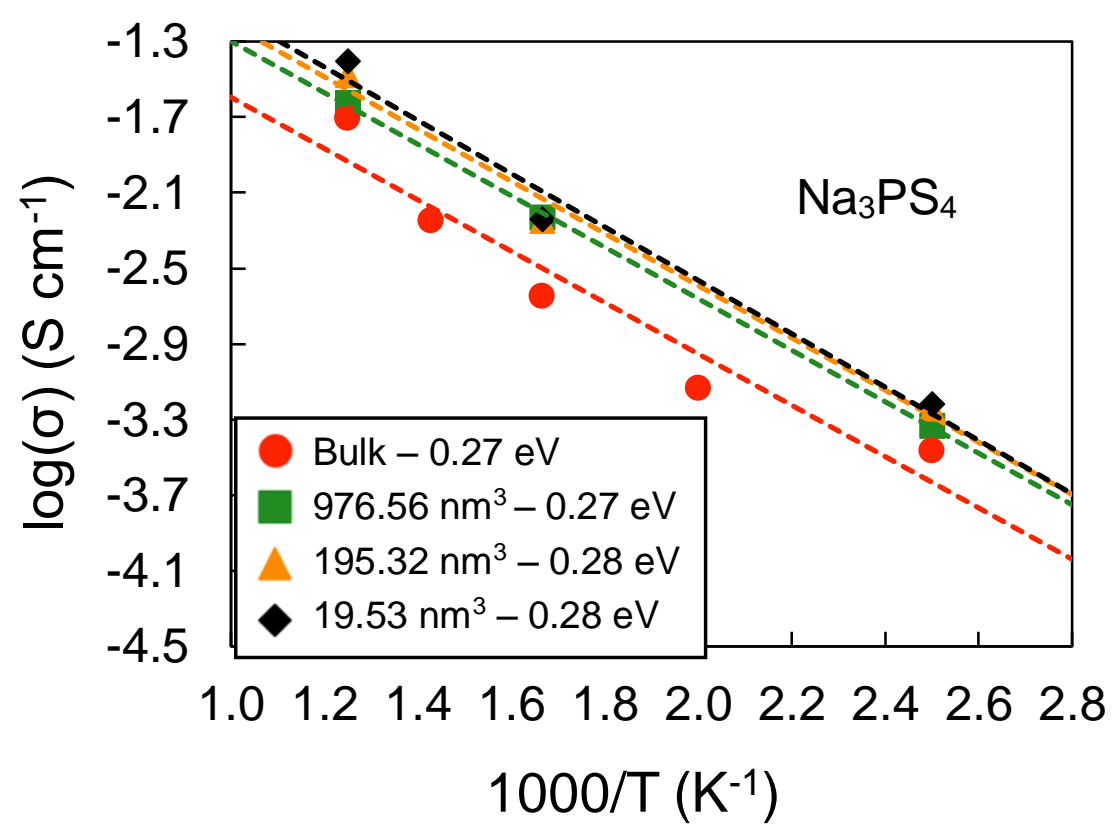

(b)

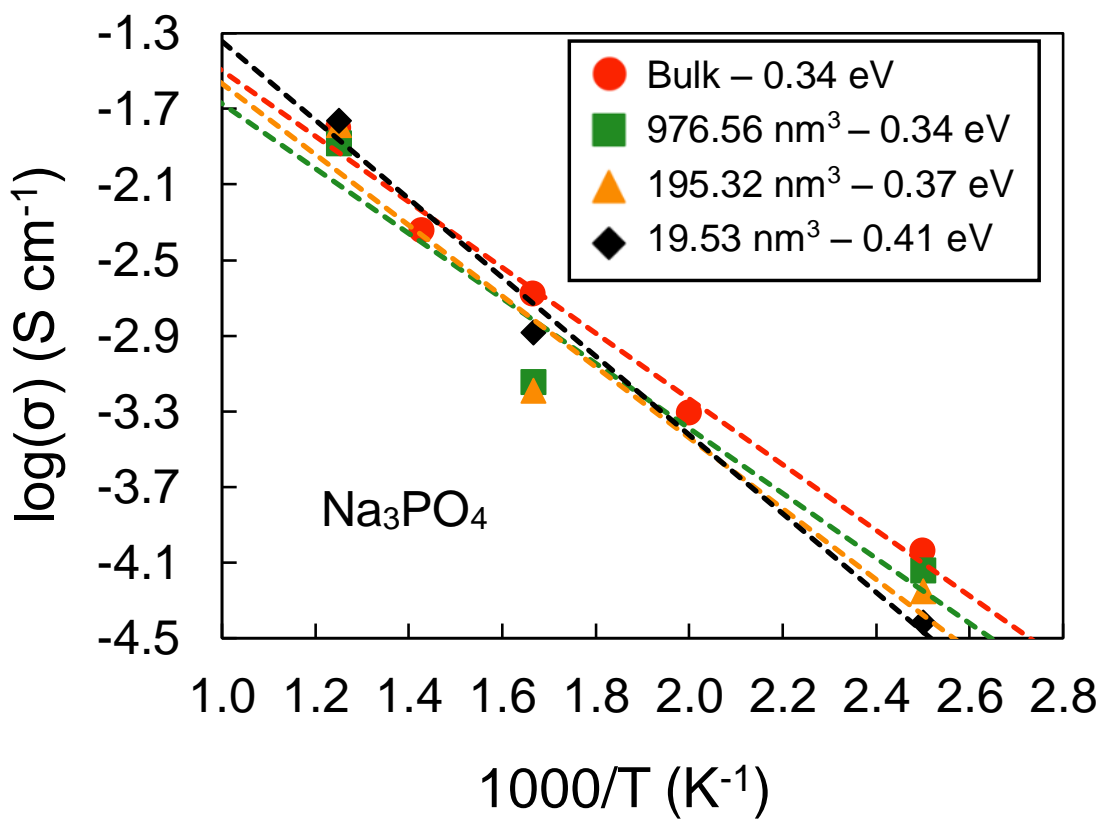

Figure S4. Na-ion conductivities $(\sigma)$ and activation energies $\left(E_{\mathrm{a}}\right)$ for bulk and polycrystalline (for three different grain volumes of 976.56, 195.31 and $19.53 \mathrm{~nm}^{3}$ ) (a) $\mathrm{Na}_{3} \mathrm{PS}_{4}$ and (b) $\mathrm{Na}_{3} \mathrm{PO}_{4}$. 
(F) $\mathrm{PS}_{4}$ and $\mathrm{PO}_{4}$ orientation

(a)

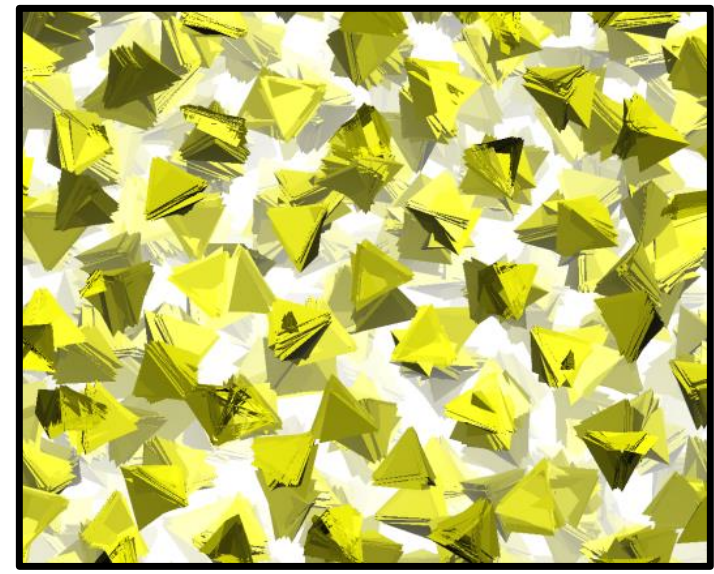

(b)

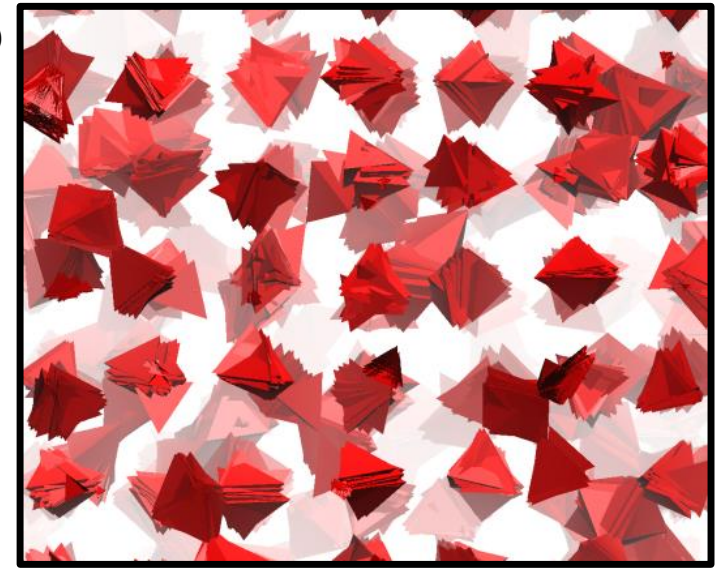

Figure S5. Orientation of (a) $\mathrm{PS}_{4}$ and (b) $\mathrm{PO}_{4}$ tetrahedra in bulk $\mathrm{Na}_{3} \mathrm{PS}_{4}$ and $\mathrm{Na}_{3} \mathrm{PO}_{4}$, respectively, during 10-ns simulations at $400 \mathrm{~K}$. The majority of tetrahedra maintain the same orientation throughout the simulation, with only local oscillations observed. The presence of significant tetrahedral rotation is therefore ruled out.

(G) Influence of Na vacancy concentration

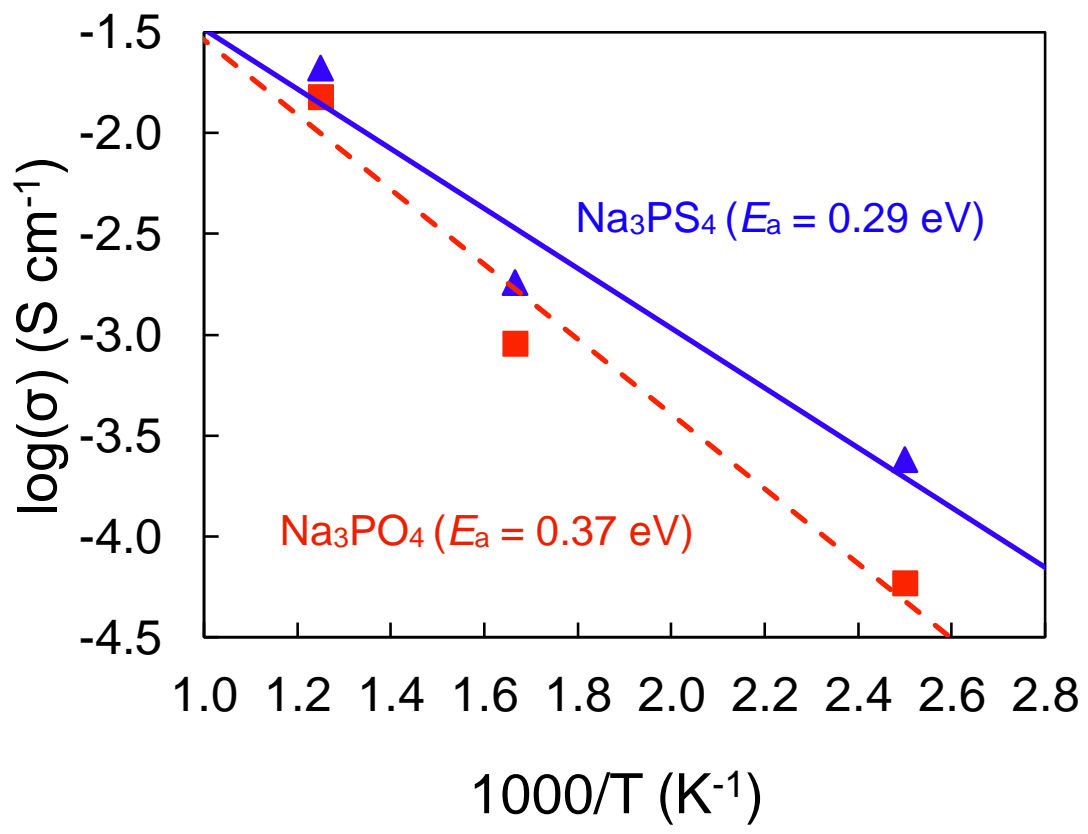

Figure S6. Na-ion conductivities $(\sigma)$ and activation energies $\left(E_{\mathrm{a}}\right)$ for bulk $\mathrm{Na}_{3} \mathrm{PS}_{4}$ and $\mathrm{Na}_{3} \mathrm{PO}_{4}$ with a Na vacancy concentration of $3 \%$. 


\section{References}

(1) Gale, J. D.; Rohl, A. L. The General Utility Lattice Program (GULP). Mol. Simul. 2003, 29, 291-341.

(2) Krauskopf, T.; Culver, S. P.; Zeier, W. G. Local Tetragonal Structure of the Cubic Superionic Conductor Na3PS4. Inorg. Chem. 2018, 57, 4739-4744.

(3) Harding, J. H. http://www.ucl.ac.uk/klmc/Potentials/Library/diller.lib (accessed Nov 12, 2018).

(4) de Klerk, N. J.; Wagemaker, M. Diffusion Mechanism of the Sodium-Ion Electrolyte $\mathrm{Na}_{3} \mathrm{PS}_{4}$ and Potential Improvements of Halogen Doping. Chem. Mater. 2016, 28, 3122.

(5) Tilocca, A.; Cormack, A. N.; de Leeuw, N. H. The Structure of Bioactive Silicate Glasses: New Insight from Molecular Dynamics Simulations. Chem. Mater. 2007, 19, 95-103.

(6) Harrison, R. J.; Putnis, A.; Kockelmann, W. Phase Transition Behaviour and Equilibrium Phase Relations in the Fast-Ion Conductor System $\mathrm{Na}_{3} \mathrm{PO}_{4}-\mathrm{Na}_{2} \mathrm{SO}_{4}$. Phys. Chem. Chem. Phys. 2002, 4, 3252-3259. 
